Check for updates

Cite this: RSC Adv., 2020, 10, 44232

Received 25th September 2020

Accepted 21st November 2020

DOI: $10.1039 / \mathrm{d} 0 \mathrm{ra0} 8206 \mathrm{f}$

rsc.li/rsc-advances

\section{Statistical optimization of photo-induced biofabrication of silver nanoparticles using the cell extract of Oscillatoria limnetica: insight on characterization and antioxidant potentiality}

\author{
Rasha A. Abo-Elmagd, ${ }^{a}$ Mervat H. Hussein, ${ }^{a}$ Ragaa A. Hamouda, ${ }^{\star b c}$ \\ Ahmed Esmail Shalan (D) *de and Ahmed Abdelrazak (D)*a
}

\begin{abstract}
Silver nanoparticles were successfully fabricated through a very simple, rapid, one-step photo-induced green approach. The formation of silver nanoparticles was accomplished using the bioactive compounds in the aqueous extract of fresh Oscillatoria limnetica biomass, which acted as a reducing and capping agent at the same time. The biosynthesis of Oscillatoria-silver nanoparticles (O-AgNPs) was investigated under the influence of different light intensities 57.75, 75.90 and $1276.51 \mu \mathrm{mol} \mathrm{m}{ }^{-2} \mathrm{~s}^{-1}$ (bright sunlight). UV-Vis (UV) and Fourier transform infrared (FT-IR) spectroscopy were applied to approve the synthesis of AgNPs. Further, the synthesis process under the exposure to sunlight was adjusted via utilizing one factor at a time, and $0.5 \mathrm{mM} \mathrm{AgNO}_{3}$ concentration, $5 \mathrm{~mL}$ O. limnetica solution, $\mathrm{pH} 6.7$ and 30 min sunlight

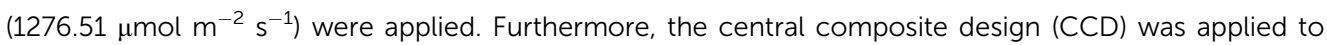
boost the biosynthesis process of O-AgNPs (manufactured at light intensity $75.90 \mu \mathrm{mol} \mathrm{m} \mathrm{m}^{-2} \mathrm{~s}^{-1}$ ). The maximum production of O-AgNPs was attained with 4 detected variables: initial $\mathrm{pH}$ level (6.7), $\mathrm{AgNO}_{3}$ concentration $(0.3 \mathrm{mM})$, O. limnetica extract concentration $(3.50 \mathrm{~mL})$ and incubation time $(48 \mathrm{~h})$. Moreover, TEM, in addition to SEM, images exposed that the biosynthesized AgNPs were quasi-spherical in shape with a small monodisperse nature, and the size range was between $6.98-23.48 \mathrm{~nm}$ in the case of light-induced synthesis $\left(75.90 \mu \mathrm{mol} \mathrm{m} \mathrm{m}^{-2} \mathrm{~s}^{-1}\right)$ and $11.58-22.31 \mathrm{~nm}$ with sunlight $\left(1276.51 \mu \mathrm{mol} \mathrm{m}^{-2} \mathrm{~s}^{-1}\right)$.
\end{abstract}

\section{Introduction}

Nano-biotechnology is a promising and emerging domain among the modern key technologies and deals with the fabrication, design and manipulation of nanoscale materials with innovative applications using the asset of biological sources that affect the characteristics of the prepared nanoparticles (NPs). Recently, nano-biotechnology has opened novel frontiers in the development of diverse disciplines, including biomedical sciences, drug-gene delivery, cancer nanotechnology, chemical industries, catalysis, cosmetics, agriculture and wastewater treatment. ${ }^{1}$ The manufacture of metal nanoparticles (MNPs) have gained great attention due to their distinctive structural

\footnotetext{
${ }^{a}$ Botany Department, Faculty of Science, Mansoura University, Mansoura, Egypt. E-mail: ahmed_bt@mans.edu.eg

${ }^{b}$ Department of Biology, Faculty of Sciences and Arts Khulais, University of Jeddah, Jeddah, Saudi Arabia.E-mail: ragaahom@yahoo.com

'Department of Microbial Biotechnology, Genetic Engineering \& Biotechnology Research Institute, Sadat University, Sadat City, Egypt

${ }^{d}$ Central Metallurgical Research and Development Institute (CMRDI), P.O. Box 87, Helwan, Cairo 11421, Egypt. E-mail: a.shalan133@gmail.com

${ }^{e}$ BCMaterials, Basque Center for Materials, Applications and Nanostructures, Martina Casiano, UPV/EHU Science Park, Barrio Sarriena s/n, Leioa 48940, Spain
}

properties, small size (1-100 nm), large surface area, high reactivity and numerous applications in several advanced areas of science, including electronic devices, biomedicine, pharmaceuticals, biomarkers, biosensors and textile industries. ${ }^{2}$ Metal nanoparticles have characteristic chemical and physical features compared with their bulk materials as a consequence of their large surface-area-to-volume ratio. ${ }^{3}$ Furthermore, the broad usage of MNPs is expected to have a significant role in increasing the extension of the macroeconomic industry in the upcoming years. ${ }^{4}$ However, the escalating toxicity and rise in the price of MNPs may be the restricting factors that can eventually decrease their market value. ${ }^{5}$ Among the different MNPs, silver nanoparticles (AgNPs) are widely utilized because of their medical, as well as pharmaceutical, applications as strong antimicrobial, antioxidant, antibiofilm and anti-inflammatory agents and as catalysts for quickening some chemical reactions. ${ }^{6}$ Additionally, AgNPs can also be specifically applied in biosensing, gene therapy, wound dressings, medical/surgical tools and water treatment.' Silver nanoparticles (AgNPs) have attained significant attention due to their efficient antimicrobial mediatory factors, which reveal low toxicity, besides their broad spectrum of in vitro and in vivo applications. ${ }^{6}$ Nowadays, several physical, chemical and biological methods are applied 
to fabricate nanoparticles. However, chemical and physical approaches for nanoparticle synthesis are widely used and effectual methodologies. Undesirably, they have some downsides, such as the use of high energy or toxic chemicals, workintensified, high cost and the release of huge amounts of harmful by-products that cause great danger to living organisms and have an unfavorable influence on environmental and medical implementation. ${ }^{8}$ Consequently, there is an obvious basic necessity for an eco-friendly, low-cost, single-step, nontoxic and biocompatible approach for nanoparticle fabrication. ${ }^{9}$ Recently, the development of green routes that can remove or reduce the production of toxic chemicals and solvents and generate a sustainable system for the manufacture of metal nanoparticles has been highlighted as an alternate methodology. ${ }^{\mathbf{1 0}}$ Thus, extracts from plants and algae, ${ }^{\mathbf{1 1}}$ bacteria $^{\mathbf{1 2}}$ and fungi ${ }^{\mathbf{1 3}}$ have become more attractive for environmentally benign biosynthesis of metallic nanoparticles. Numerous types of biomolecules in the extracts, such as enzymes, amino acids, proteins, carbohydrates, flavonoids, and terpenoids, which facilities in metal reduction and their stabilization, have been used in the biosynthesis of nanoparticles. ${ }^{\mathbf{1 4}}$ Currently, phyconanotechnology has been an interesting and approaching domain with greater options in the production of algae-mediated nanoparticles. Algae are a source of a cluster of secondary metabolites, pigments and proteins that can function as nanobiofactories of metallic nanoparticles via extracellular or intracellular reduction of metal ions to their corresponding nano-forms. ${ }^{\mathbf{1 5 - 1 9}}$ The abundance of algae and their ability for excessive metal uptake makes them an inexpensive raw material. ${ }^{20}$ The main purpose of this work was to achieve eco-friendly, and green photo-synthesis of stable silver nanoparticles (AgNPs) from the aqueous extract of Oscillatoria limnetica by photoinduction. The biosynthesis process was investigated using the central composite design (CCD) to get the optimum concentration of $\mathrm{O}$. limnetica, $\mathrm{pH}$, incubation period and concentration of $\mathrm{AgNO}_{3}$ for the preparation of AgNPs. Additionally, the characterization of the optimized biosynthesized AgNPs was executed by transmission electron microscopy (TEM), scanning electron microscopy (SEM), zeta potential calculation, as well as particle size analysis. Further, the antioxidant features of the attained AgNPs were estimated via the DPPH, ABTS, and erythrocyte assays.

\section{Materials and methods}

\section{Oscillatoria limnetica culture environment and preparation of its extract}

The cyanobacterium Oscillatoria limnetica was obtained from the algal culture collection of the phycology laboratory at Mansoura University. Besides, the axenic inoculum was cultured inside $500 \mathrm{~mL}$ Erlenmeyer flasks containing $200 \mathrm{~mL}$ of BG11 medium ${ }^{21}$ and incubated at $28 \pm 1{ }^{\circ} \mathrm{C}$ under incessant illumination (57.75 $\mu \mathrm{mol} \mathrm{m} \mathrm{m}^{-2} \mathrm{~s}^{-1}$ ) for almost 22 days at the start of the stationary growth stage. Furthermore, the synthesis of the extract was conducted according to ref. 22. For the preparation of the extract, fresh algal biomass was harvested from $200 \mathrm{~mL}$ of the culture by centrifugation at $1610 \times g$ for 10 min using a centrifuge
(Centurion Scientific, United Kingdom). Then, the obtained pellet corresponding to $0.154 \mathrm{~g}$ dry biomass per $\mathrm{L}$ was suspended in $10 \mathrm{~mL}$ deionized water and sonicated for $15 \mathrm{~min}$ at amplitude 100 using an ultrasonic homogenizer (Cole-Parmer instrumental Co. Chicago, Illinois 66648 USA). The homogenous suspension was made up to $100 \mathrm{~mL}$ with deionized water and stored at $4{ }^{\circ} \mathrm{C}$ for future use. In addition, the $O$. limnetica extract was chemically analysed for determining the content of light-harvesting pigments, ${ }^{23}$ proteins $^{24}$ and total soluble sugars. ${ }^{25}$

\section{Light-mediated biosynthesis of Oscillatoria-silver nanoparticles}

The silver source for AgNP production was silver nitrate powder (analytical grade $\mathrm{AgNO}_{3}$ with high purity). In this study, a $0.5 \mathrm{mM} \mathrm{AgNO}_{3}$ stock solution was prepared with distilled $\mathrm{H}_{2} \mathrm{O}$ and stored in a brown bottle at $4{ }^{\circ} \mathrm{C}$ for further use.

The cyanobacterial extract was used as the bio-mediator for the fabrication of AgNPs. The light-induced biosynthesis of Oscillatoria-silver nanoparticles (O-AgNPs) was conducted by following the protocol of Hamouda et al. ${ }^{22}$ The synthetic reaction was carried out by incubating the $O$. limnetica extract $(5 \mathrm{~mL}$ of the prepared homogenous solution was made up with $(0.1 \mathrm{M})$ phosphate buffer at $\mathrm{pH} 7$ to $19 \mathrm{~mL}$ ) with $1 \mathrm{~mL} \mathrm{AgNO}_{3}$ solution (0.5 mM). The bio-reduction of O-AgNPs was accomplished using the following three light intensities: 57.75 (4273.5 lux), 75.90 (5616.6 lux) and 1276.51 (68931 lux) $\mu \mathrm{mol} \mathrm{m} \mathrm{m}^{-2} \mathrm{~s}^{-1}$. The first two light intensities were achieved by incubating the mixtures at $35 \pm 1{ }^{\circ} \mathrm{C}$ for 48 hours under the direct illumination of $36 \mathrm{~W}$ white fluorescent lamps, while $1276.51 \mu \mathrm{mol} \mathrm{m} \mathrm{m}^{-2} \mathrm{~s}^{-1}$ (68931 lux) light intensity was achieved with incubation under direct sunlight on a summer day $\left(39^{\circ} \mathrm{C}\right)$ at noon for 30 minutes. This condition was chosen after investigating the optimum period of sunlight exposure (5-30 $\mathrm{min}$ ) and bio-reduction in the dark condition by keeping the mixtures in a closed container at the temperature and light intensity of $30{ }^{\circ} \mathrm{C}$ and 0 lux, respectively. The reaction mixtures revealed an instantaneous change in color from greenish to dark brown, signifying the synthesis of AgNPs. After the incubation time, the reduction of silver ions was assessed by measuring the absorption in the range of 200$900 \mathrm{~nm}$ using a UV-visible spectrophotometer (ATI Unicam 5625 UV/VIS Vision Software V3.20). Then, the reaction mixtures were centrifuged at $4528 \times g$ for 10 min using a centrifuge (MIKRO 12 Hettich Zentrifugen D-78532 Tuttlingen-Germany) to separate the AgNPs. For complete purification, the precipitated Ag nanoparticles were washed 5 times with deionized water. Additionally, the obtained AgNPs were dried and stored for further examination.

\section{Optimization of O-AgNP biosynthesis using the central composite design (CCD)}

The response surface methodology (RSM) was employed to explore potential interactions among the selected significant parameters that influence the production of O-AgNPs. The central composite design (CCD) proposed by McDonald et al. ${ }^{26}$ is a proficient statistical method that is applied for sequential experimentation to evaluate the optimization of variables and 
responses. The initial $\mathrm{pH}$ level $\left(X_{1}\right), \mathrm{AgNO}_{3}$ concentration $(\mathrm{mM})$ $\left(X_{2}\right)$, O. limnetica extract concentration $(\mathrm{mL})\left(X_{3}\right)$ and incubation period (h) $\left(X_{4}\right)$ are the main parameters that influence the $O$. limnetica-mediated synthesis of silver nanoparticles. ${ }^{22}$ They were used for optimizing the synthetic process via the central composite design (CCD). Furthermore, a matrix consisting of 31-trials was employed, and each factor was tested at five levels (coded, $-2,-1,0,+1,+2$ and each trial was conducted in duplicate). The CCD matrix included seven center points and star points to assess the twist, which facilitates the prediction of noteworthy deficiency in the fitting of the statistical representations. The optical density (OD) that achieved the highest production of AgNPs at the wavelength of $430 \mathrm{~nm}$ was considered as a function in calculating the AgNP yield, which represents the reliance of the response $(Y)$ on a variable. All the optimized silver nanoparticle samples were characterized via UV-Vis spectroscopy after each trail of AgNP synthesis, and the computed responses were the optical density values $\left(\mathrm{OD}_{430}\right)$.

Additionally, the CCD experimental data were tailored through the response surface regression method via the next second-order polynomial equation.

$$
Y=\beta_{0}+\sum_{i} \beta_{i} X_{i}+\sum_{i i} \beta_{i i} X_{i}^{2}{ }_{i}+\sum_{i j} \beta_{i j} X_{i} X_{j}
$$

$Y$ represents the predicted response, $\beta_{0}$ represents the regression coefficients, $\beta_{i}$ represents the linear coefficients, $\beta_{i i}$ represents the quadratic coefficients, $\beta_{i j}$ represents the interaction coefficients, and $X_{i}$ represents the coded levels of the independent variables. Besides, the analysis of variances (ANOVA) was conducted via the Design Expert 8.0 statistical package (statEase, Inc, Minneapolis, MN, USA).

\section{Characterization of O-AgNPs}

Confirmation of O-AgNP formation was attained by analyzing the absorption spectra of the biofabricated O-AgNPs via the UV-Vis spectroscopy technique (ATI Unicam 5625 UV/VIS Vision Software V3.20). Furthermore, to detect the biomolecules that lead to the reduction of $\mathrm{Ag}^{+}$ions in addition to the capping of O-AgNPs, Fourier transforms infrared (FTIR) spectroscopy was used (ThermoFisherscientific Nicolete IS10, USA) in the window of 4000 to $500 \mathrm{~cm}^{-1}$ at a resolution of $1 \mathrm{~cm}^{-1}$, and the biofabricated AgNPs were lyophilized and diluted using $\operatorname{KBr}(1: 100)$ to prepare a pellet. Besides, transmission electron microscopy (TEM) was applied to elucidate the accurate morphology, shape and particle size of the biosynthesized O-AgNPs (JEOL, JEM-2100, Japan). SEM analysis was utilized to investigate the surface characteristics (JEOL JSM-6510/v, Japan). In addition, the size, distribution and surface charge of the biogenic nanoparticles were determined using the zeta potential and particle size analyzer (Malvern Zeta sizer Nano-ZS90, UK).

\section{Biotechnological applications of O-AgNPs (antioxidant capacity of the photo-synthesized O-AgNPs)}

The optimized photo-synthesized O-AgNPs (at the light intensity of $75.90 \mu \mathrm{mol} \mathrm{m} \mathrm{m}^{-2} \mathrm{~s}^{-1}$ ) were used for studying the antioxidant potentiality as follows:
DPPH free radical scavenging assay. 1,1-diphenyl-2-picrylhydrazyl (DPPH), a stable free radical compound, was applied to study the radical-scavenging activity of the produced $\mathrm{O}$ AgNPs, according to Mani et al. ${ }^{27}$ O-AgNPs at the following concentrations: $20,40,60,80$ and $100 \mu \mathrm{g} \mathrm{mL}{ }^{-1}$ were mixed with $1 \mathrm{~mL}$ of $0.1 \mathrm{mM}$ DPPH solution and made up to $3 \mathrm{~mL}$ with methanol. Thereafter, the reaction mixtures were vigorously shaken and incubated at $37^{\circ} \mathrm{C}$ for $30 \mathrm{~min}$. The reduction of the $\mathrm{DPPH}$ free radical was quantified by measuring the absorbance at $517 \mathrm{~nm}$ using the ascorbic acid solution $\left(0.01 \mathrm{mg} \mathrm{mL}^{-1}\right)$ as the positive control. Besides, the free-radical-scavenging potential (reducing power) of O-AgNPs was evaluated via the below relationship:

$$
\text { DPPH scavenging effect }(\%)=100 \times\left(A_{\mathrm{o}}-A_{1}\right) /\left(A_{\mathrm{o}}\right)
$$

where $A_{\mathrm{o}}$ represents the absorbance of the control reaction, and $A_{1}$ represents the absorbance of the reaction mixture. The antioxidant activities of the nano-preparations are presented as $\mathrm{IC}_{50}$ values, which is the concentration of the extract that inhibits the formation of DPPH radicals by $50 \%$, as indicated by the linear regression analysis. ${ }^{28}$

ABTS radical-scavenging assay. The ABTS radical-scavenging assay was conducted by following the protocol of Re et al. ${ }^{29}$ The bluish-green ABTS [2,2'-azino-bis(3-ethyl benzothiazoline-6sulfonic acid)] radical was generated through the oxidation reaction resulting from mixing ABTS $(7 \mathrm{mM})$ with potassium persulphate $(2.45 \mathrm{mM})$. Then, the mixture was allowed to stand in the dark overnight for the formation of ABTS radicals (ABTS ${ }^{+}$) and diluted with distilled $\mathrm{H}_{2} \mathrm{O}$ to achieve an absorbance value of 1.00 at $734 \mathrm{~nm}$, which was used for evaluating the antioxidant potentiality of the O-AgNP preparations. The reactivity of the ABTS cation radical enabled the investigation of antioxidants, including phenolic, thiols and ascorbic acids. ${ }^{30}$ The antioxidant activity is presented as the percent of inhibition and was calculated as follows using ascorbic acid ( $2 \mathrm{mM})$ as the positive control.

$$
\% \text { Inhibition }=\left[A(\text { control })-\frac{A(\text { test })}{A(\text { control })}\right] \times 100
$$

Antioxidant activity screening assay for erythrocyte hemolysis. Hemolysis is the consequence of a disorder in the integrity of the erythrocyte membrane, resulting in haemoglobin leakage into the blood plasma. The method applied for determining haemolysis was according to Morimoto et $a .^{31}$

\section{Results and discussion}

\section{Confirmation of O-AgNPs using spectral analysis}

The biosynthesis of silver nanoparticles was performed using the cyanobacterial extract of $O$. limnetica. The greenish aqueous O. limnetica extract was treated with $1 \mathrm{~mL}$ of an $\mathrm{AgNO}_{3}(0.5 \mathrm{mM})$ solution after incubation under a light. In this reaction, the color of the $\mathrm{Ag}^{+} / O$. limnetica reaction mixtures changed from the initial green to yellow and finally to brown as the reaction time increased, signifying bio-reduction and the formation of $\mathrm{O}$ - 

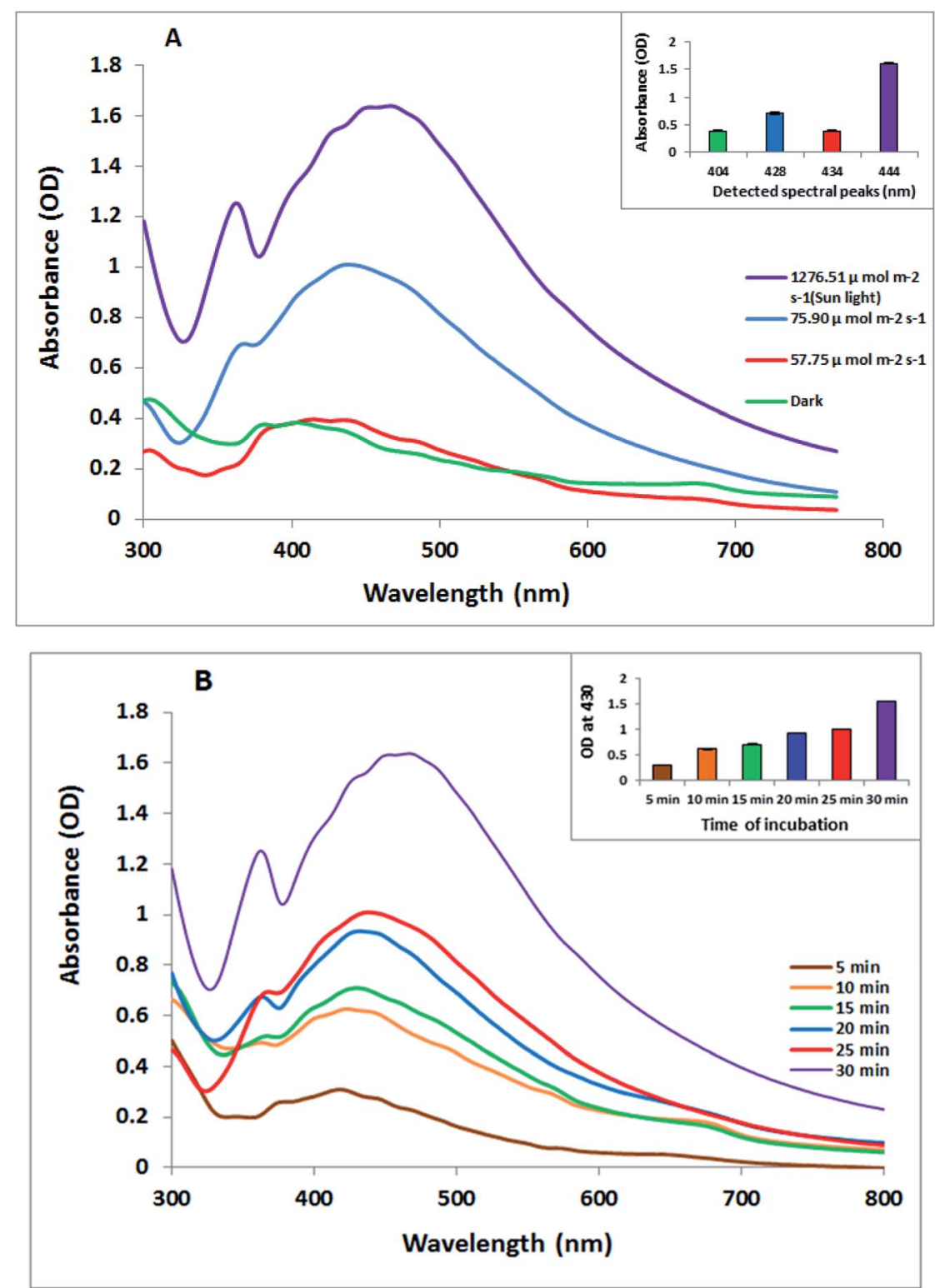

Fig. 1 (A) UV-visible absorption spectra of the photo-synthesized O. limnetica silver nanoparticles (O-AgNPs) recorded as a function of different light intensities: $57.75,75.90$ and $1276.51 \mu \mathrm{mol} \mathrm{m} \mathrm{m}^{-2} \mathrm{~s}^{-1}$ (sunlight) and in the dark (conditions: 0 . limnetica extract solution $5 \mathrm{~mL}$ and $0.5 \mathrm{mM}$ $\mathrm{AgNO}_{3}$ solution), and (B) the UV-visible absorption spectra of O-AgNPs recorded at different reaction times from 5 to 30 min under bright sunlight exposure $\left(1276.51 \mu \mathrm{mol} \mathrm{m} \mathrm{m}^{-2} \mathrm{~s}^{-1}\right)$.

AgNPs of various particle sizes. ${ }^{32}$ The change in color was attributed to the excitation of the surface plasmon absorption of the formed O-AgNPs, ${ }^{33}$ as investigated by UV-Vis spectroscopy, since previous studies have indicated that the positioning of a strong and broad SPR peak between 400-500 nm confirms the formation of AgNPs. ${ }^{34}$ From the UV-Vis absorption spectrum, certain information about the size and shape of the synthesized AgNPs could be detected. The UV-Vis absorption spectrum of the photo-synthesized O-AgNPs from O. limnetica is shown in Fig. 1A. Additionally, the O-AgNPs revealed distinctive bands between 400 and $500 \mathrm{~nm}$ owing to surface plasmon resonance, and the broad plasmon peak that prolonged from 400 to $500 \mathrm{~nm}$ might be owing to the multi-size distribution of the photo- biofabricated AgNPs. As shown in Fig. 1A, absorption peaks were detected at the following wavelengths: 434, 428, 444 and $404 \mathrm{~nm}$, giving the maximum optical intensities of 0.393, 0.709, 1.607 and $0.383 \mathrm{~nm}$ in the light regimes of $57.75,75.90$ and $1276.51 \mu \mathrm{mol} \mathrm{m} \mathrm{m}^{-2} \mathrm{~s}^{-1}$ (sunlight) and the dark, respectively, because of the formation of O-AgNPs. Interpretation of the current data led to the conclusion that the biosynthetic process of O-AgNPs using the O. limnetica extract in the dark might be dependent on proteins, soluble sugars, and polysaccharides, as well as reductases. The light-mediated biosynthesis of AgNPs demonstrated the necessity of the coordinated roles of lightharvesting pigments along with intracellular cell components, most certainly proteins and carbohydrates. ${ }^{35}$ These results 
Table 1 Phytochemical analysis of the O. limnetica extract

\begin{tabular}{|c|c|c|c|c|c|c|}
\hline \multirow[b]{2}{*}{$\begin{array}{l}\text { Total carbohydrates } \\
\left(\mathrm{mg} \mathrm{g}^{-1} \text { dry wt) }\right.\end{array}$} & \multirow[b]{2}{*}{$\begin{array}{l}\text { Protein (mg/g } \\
\text { day biomass) }\end{array}$} & \multicolumn{2}{|c|}{$\begin{array}{l}\text { Photosynthetic pigments } \\
\left(\mathrm{mg} \mathrm{g}^{-1}\right)\end{array}$} & \multicolumn{3}{|c|}{ Phycobiliproteins $\left(\mathrm{mg} \mathrm{mL}^{-1}\right)$} \\
\hline & & $\begin{array}{l}\text { Chlorophyll } \\
\mathrm{a}\left(\mathrm{mg} \mathrm{g}^{-1}\right)\end{array}$ & $\begin{array}{l}\text { Carotenoids } \\
\left(\mathrm{mg} \mathrm{g}^{-1}\right)\end{array}$ & Phycocyanin & Phycoerythrin & Allophycocyanin \\
\hline 306.667 & 225.455 & 18.06 & 2.27 & 0.313 & 0.087 & 0.169 \\
\hline
\end{tabular}

could be attributed to the concentration and particle size of biosynthesized AgNPs. ${ }^{36}$ An approximate biochemical composition showing the light-harvesting pigment content in the $O$. limnetica aqueous extract is demonstrated in Table 1. Some postulations have previously suggested that the mechanism of the reduction of silver cations involves three characteristic electron-donating bio-catalysts, including protein/enzymes, ${ }^{37}$ polysaccharides $^{38}$ and light-harvesting pigments. ${ }^{39}$ The interpretation is that AgNP biosynthesis might be achieved in twosteps: the silver cations would adhere to the algal cell surface in the aqueous medium due to the electrostatic attraction between the metal cations and the negatively charged cell wall, and then, metal cations would be reduced to the nano-form by the cellular reductases. ${ }^{40}$ Respecting to the presence of extracellular reductases such as nitrate reductases of Scenedesmus obliquus culture that using as reducing agents are supposed to have an essential role in the extracellular formation of AgNPs. ${ }^{2}$ In addition, the findings of Mukherjee et al. have documented their contribution towards the extracellular production of AgNPs using the Bacillus clausii culture. ${ }^{41}$ Studies have documented the role of protein molecules as both reducing and capping agents in the biogenic preparation of AgNPs besides their role toward stabilizing the AgNP preparations. ${ }^{16,35,37,42}$ Microbial EPS composed of proteins, polysaccharides, lipids, and some inorganic substances can function as a reducing and stabilizing agent in the biosynthesis of AgNPs. ${ }^{43}$ Light-induced procedures for the fabrication of nanoparticles are based on the reduction of the metal cation $\mathrm{Mn}^{+}$to $\mathrm{Mn}^{0}$ by a direct or indirect pathway via photosystem II. ${ }^{32}$ Herein, the presence of $O$. limnetica phycobilisomes, which contain phycobiliproteins (colored protein-based pigments), and chlorophyll a-luxuriant thylakoids that assisted conformational alterations to absorb light energy for initiating photosynthesis. Excitation of the molecules from the ground state to an electronically excited state is mediated by chromospheres after absorbing light. ${ }^{44}$ Therefore, the proposed explanation is, under illumination, the electrons that jump between energy levels can as well reduce $\mathrm{AgNO}_{3}$ in the medium to produce silver nanoparticles.

Consequently, the optimal time for the sunlight-mediated biosynthesis of AgNPs (Fig. 1B) was obtained by monitoring the biofabrication of AgNPs under sunlight (5-30 min) at $5 \mathrm{~min}$ intervals, and the other experimental parameters were maintained at the same level $(5 \mathrm{~mL}$ of $O$. limnetica aqueous solution and $1 \mathrm{mM}$ silver nitrate solution). Besides, it was noticed that once the reaction mixture was exposed to bright sunlight, the physical appearance of the solution modified instantly, showing a rise in the intensity of color to deep brown with exposure time.
We could notice that the absorbance was directly related to exposure time, as the absorbance value increased on increasing the exposure time, achieving its maximum value at $30 \mathrm{~min}$. Interestingly, the peak maxima for exposure to diverse sunlight durations while the peak maxima was documented at $444 \mathrm{~nm}$ for $30 \mathrm{~min}$ of sunlight demonstrated that the size of O-AgNPs increased as the reaction time increased. ${ }^{44}$ The photomediated synthesis of O-AgNPs was initiated by the absorption of light by the photosensitive molecules present in the $O$. limnetica extract (Table 1). ${ }^{45}$ Consequently, 30 min under bright sunlight was measured as the ideal time for the photo-induced biofabrication of O-AgNPs and was used for additional characterization.

\section{FTIR spectroscopy of the photo-synthesized O-AgNPs}

FTIR spectroscopic analysis was conducted to describe the biomolecules involved in reducing the $\mathrm{Ag}^{+}$ions and in capping and stabilizing the biofabricated O-AgNPs. ${ }^{\mathbf{4}}$ The FTIR spectra of AgNPs photo-fabricated using O. limnetica are represented in Fig. 2. The FTIR analysis of the photo-synthesized O-AgNPs at the light intensity of $75.90 \mu \mathrm{mol} \mathrm{m} \mathrm{m}^{-2} \mathrm{~s}^{-1}$ (fluorescent light) showed 10 major absorption peaks at 3420, 2926, 2854, 1734, 1651, 1384, 1132, 1040, $826 \& 542 \mathrm{~cm}^{-1}$ (Fig. 2A), while that of the O-AgNPs synthesized under exposure to sunlight (1276.51 $\mu \mathrm{mol} \mathrm{m} \mathrm{m}^{-2} \mathrm{~s}^{-1}$ ) revealed 10 major spectral bands (Fig. 2B) having the subsequent wavenumbers 3448, 2925, 2855, $1740,1635,1384,1082,1032,816 \& 460 \mathrm{~cm}^{-1}$. In the dark condition, the FTIR investigation of the O-AgNP reaction mixture (Fig. 2C) revealed 9 major spectral bands at 3430, 2924, $2854,1760,1637,1383,1034,824 \& 673 \mathrm{~cm}^{-1}$. In the spectra obtained, the characteristic broad sharp bands at around 3420$3448 \mathrm{~cm}^{-1}$ corresponded to the strong stretching vibration of the hydroxyl groups $(\mathrm{O}-\mathrm{H})$ in phenols and flavonoids, and the $\mathrm{N}-\mathrm{H}$ stretching vibration in peptides and proteins. These results indicate the role of the biological molecules in the $O$. limnetica extract in the bioreduction of silver ions to $\mathrm{AgNPs}^{47}$ and the role of proteins in stabilizing and preventing the agglomeration of AgNPs. ${ }^{48}$ The bands observed at 2924 and $2854 \mathrm{~cm}^{-1}$ were possibly due to the $\mathrm{C}-\mathrm{H}$ stretching vibration of alkanes and the $\mathrm{N}-\mathrm{H}$ bending vibration..$^{49}$ On the other hand, the absorption peaks at $1734-1760 \mathrm{~cm}^{-1}$ corresponded to the aldehydic group $(\mathrm{C}=\mathrm{O}),{ }^{50}$ while the bands in the range 1635$1651 \mathrm{~cm}^{-1}$ could be assigned to amide $(\mathrm{N}-\mathrm{H})$ stretching and the $\mathrm{C}=\mathrm{C}$ stretching of the peptide linkages in proteins, which also indicate the involvement of proteins in the stabilization of AgNPs. ${ }^{38}$ The absorption peak at $1384 \mathrm{~cm}^{-1}$ could be attributed to the residual amount of $\mathrm{AgNO}_{3} \cdot{ }^{51}$ Meanwhile, the absorption 
(A)

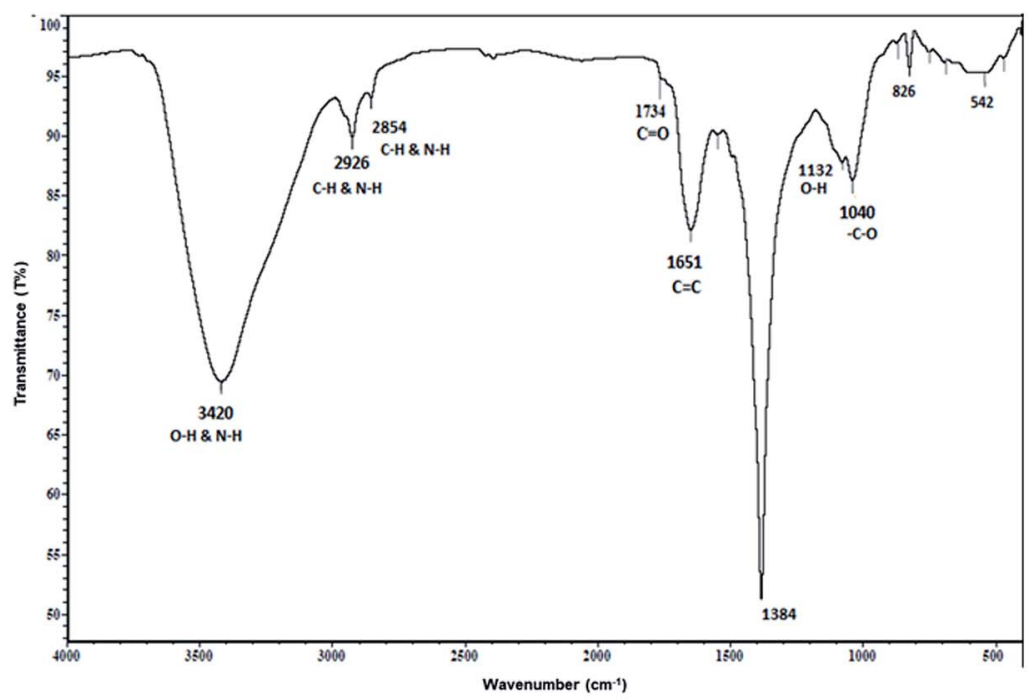

(B)

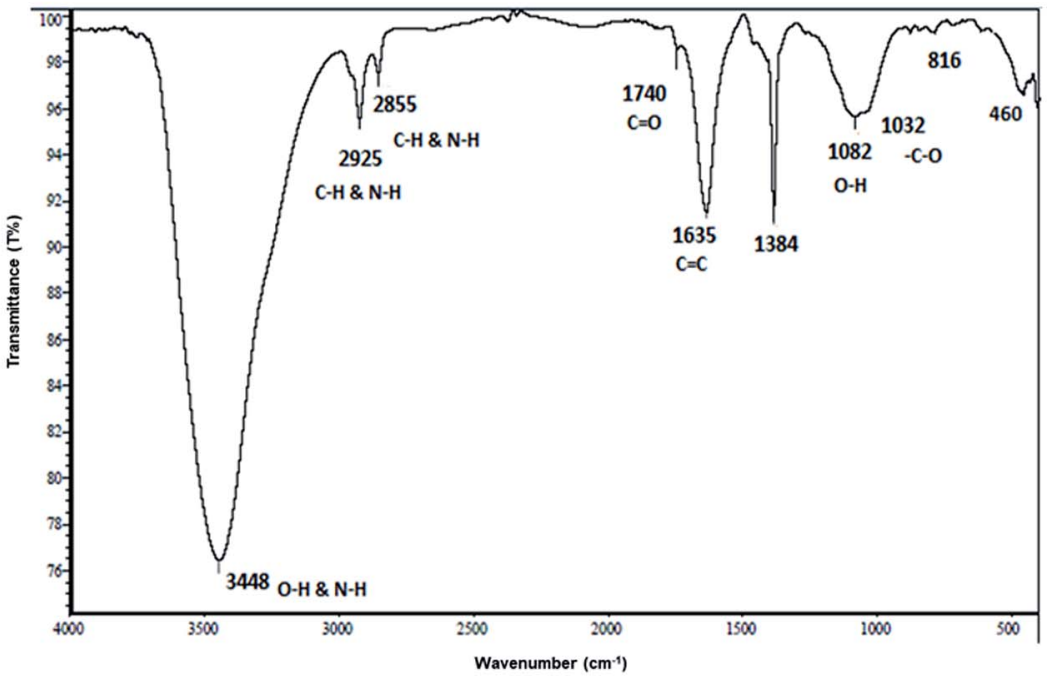

(C)

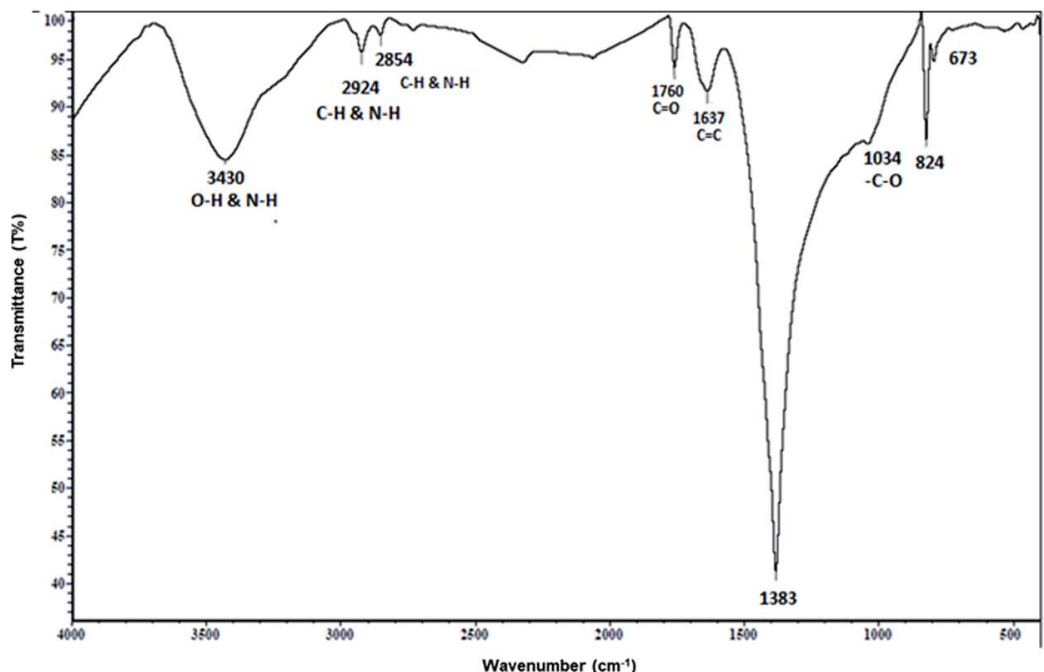

Fig. 2 FTIR spectra of the photo-synthesized O. limnetica silver nanoparticles (O-AgNPs) recorded as a function of light intensity: (A) 75.90 (fluorescent light), (B) $1276.51 \mu \mathrm{mol} \mathrm{m} \mathrm{m}^{-2} \mathrm{~s}^{-1}$ (sunlight) and (C) in the dark.

bands observed at 1132 and 1082 could be matched to the C-N aliphatic and aromatic amine stretching vibrations. The peaks at $1034-1040 \mathrm{~cm}^{-1}$ could be assigned to the absorption of the
-C-O bond. The absorption bands observed at 816,673, 542 and $460 \mathrm{~cm}^{-1}$ could be attributed to the bending areas of the aliphatic chains. Furthermore, the spectral bands at 1384, 1132 
Table 2 Coded and actual values of the experimental variables used for the CCD matrix

\begin{tabular}{|c|c|c|c|c|c|c|}
\hline \multirow[b]{2}{*}{ Variable } & \multirow[b]{2}{*}{ Variable code } & \multicolumn{5}{|c|}{ Levels } \\
\hline & & -2 & -1 & 0 & 1 & 2 \\
\hline $\mathrm{AgNO}_{3}$ concentration $(\mathrm{mM})$ & $X_{2}$ & 0.1 & 0.2 & 0.3 & 0.4 & 0.5 \\
\hline O. limnetica extract concentration $(\mathrm{mL})$ & $X_{3}$ & 1 & 2.25 & 3.50 & 4.75 & 6 \\
\hline Incubation period (h) & $X_{4}$ & 48 & 37.5 & 27 & 16.5 & 6 \\
\hline
\end{tabular}

$\& 1034 \mathrm{~cm}^{-1}$ corresponded to either sulfur or phosphorus active groups that accomplish both capping and stabilization of AgNPs. ${ }^{38}$

\section{Statistical optimization of O-AgNP biofabrication using the response surface methodology (RSM)}

Herein, a CCD matrix was applied for optimizing the yield of $\mathrm{O}$ AgNPs in terms of optical intensity. CCD is an array of mathematical and statistical practices used for approximating and optimizing the values of the most effectual variables in O-AgNP biofabrication. It was used also to examine their relationships. Depending on the one-factor-based experimental results, four independent variables were chosen as follows: $X_{1}$ (initial $\mathrm{pH}$ level), $X_{2}\left(\mathrm{AgNO}_{3}\right.$ concentration - mM), $X_{3}$ (O. limnetica extract concentration $-\mathrm{mL}$ ) and $X_{4}$ (incubation period $-\mathrm{h}$ ) (Table 2). The resultant CCD matrix and the responses of the design are demonstrated in Table 3, which shows thirty-one trails including 16 cube, 8 axial and 7 central points. The seven central points obtained are represented in standard order 25 , 26, 27, 28, 29, 30 and 31. The optimum variable levels for the maximum O-AgNP yield $(0.8695 \mathrm{~nm})$ were attained in trial number 24, in which $X_{1}=6.7 \mathrm{pH}, X_{2}=0.3 \mathrm{mM}, X_{3}=3.50 \mathrm{~mL}$ and $X_{4}=48$ hours. Optimizing the parameters caused a significant increase in O-AgNP yield, which was $22.45 \%$ prior to optimization. The level of significance was measured at a $90 \%$ level of confidence, and $P$-values $<0.1$ were deliberated as

Table 3 Central composite design (CCD) matrix of the four parameters with the experimental values from photo-induced O-AgNP biosynthesis (light intensity: $75.90 \mu \mathrm{mol} \mathrm{m} \mathrm{m}^{-2} \mathrm{~s}^{-1}$ )

\begin{tabular}{|c|c|c|c|c|c|}
\hline Std. order & $\begin{array}{l}\text { Initial pH level } \\
\left(X_{1}\right)\end{array}$ & $\begin{array}{l}\mathrm{AgNO}_{3} \text { concentration } \\
(\mathrm{mM})\left(X_{2}\right)\end{array}$ & $\begin{array}{l}\text { O. limnetica } \\
\text { extract concentration }(\mathrm{mL})\left(X_{3}\right)\end{array}$ & $\begin{array}{l}\text { Incubation period } \\
\text { (h) }\left(X_{4}\right)\end{array}$ & Intensity (nm) \\
\hline 1 & 5.7 & 0.2 & 2.25 & 16.5 & -0.0016 \\
\hline 2 & 7.7 & 0.2 & 2.25 & 16.5 & 0.0060 \\
\hline 3 & 5.7 & 0.4 & 2.25 & 16.5 & -0.0022 \\
\hline 4 & 7.7 & 0.4 & 2.25 & 16.5 & 0.0391 \\
\hline 5 & 5.7 & 0.2 & 4.75 & 16.5 & -0.0221 \\
\hline 6 & 7.7 & 0.2 & 4.75 & 16.5 & 0.0043 \\
\hline 7 & 5.7 & 0.4 & 4.75 & 16.5 & -0.0516 \\
\hline 8 & 7.7 & 0.4 & 4.75 & 16.5 & 0.3450 \\
\hline 9 & 5.7 & 0.2 & 2.25 & 37.5 & 0.0326 \\
\hline 10 & 7.7 & 0.2 & 2.25 & 37.5 & 0.3054 \\
\hline 11 & 5.7 & 0.4 & 2.25 & 37.5 & 0.2855 \\
\hline 12 & 7.7 & 0.4 & 2.25 & 37.5 & 0.3064 \\
\hline 13 & 5.7 & 0.2 & 4.75 & 37.5 & 0.3220 \\
\hline 14 & 7.7 & 0.2 & 4.75 & 37.5 & 0.4584 \\
\hline 15 & 5.7 & 0.4 & 4.75 & 37.5 & 0.3866 \\
\hline 16 & 7.7 & 0.4 & 4.75 & 37.5 & 0.6753 \\
\hline 17 & 4.7 & 0.3 & 3.50 & 27.0 & -0.0029 \\
\hline 18 & 8.7 & 0.3 & 3.50 & 27.0 & 0.1670 \\
\hline 19 & 6.7 & 0.1 & 3.50 & 27.0 & 0.0427 \\
\hline 20 & 6.7 & 0.5 & 3.50 & 27.0 & 0.1479 \\
\hline 21 & 6.7 & 0.3 & 1.00 & 27.0 & 0.1133 \\
\hline 22 & 6.7 & 0.3 & 6.00 & 27.0 & 0.2255 \\
\hline 23 & 6.7 & 0.3 & 3.50 & 6.0 & 0.2979 \\
\hline 24 & 6.7 & 0.3 & 3.50 & 48.0 & 0.8695 \\
\hline 25 & 6.7 & 0.3 & 3.50 & 27.0 & 0.4324 \\
\hline 26 & 6.7 & 0.3 & 3.50 & 27.0 & 0.4324 \\
\hline 27 & 6.7 & 0.3 & 3.50 & 27.0 & 0.4309 \\
\hline 28 & 6.7 & 0.3 & 3.50 & 27.0 & 0.4319 \\
\hline 29 & 6.7 & 0.3 & 3.50 & 27.0 & 0.4331 \\
\hline 30 & 6.7 & 0.3 & 3.50 & 27.0 & 0.4339 \\
\hline 31 & 6.7 & 0.3 & 3.50 & 27.0 & 0.4324 \\
\hline
\end{tabular}


Table 4 Regression statistics of CCD: the regression coefficients and analysis of variance (ANOVA) of the CCD model for the photo-induced OAgNP biofabrication process using $O$. limnetica extract. df: degree of freedom, *significant values, F: Fishers's function, $P$ : level of significance, C. $\vee$ : coefficient of variation

\begin{tabular}{|c|c|c|c|c|c|}
\hline Source & Sum of squares & df & $F$-value & $\begin{array}{l}P \text {-value } \\
\text { prob }>F\end{array}$ & $\begin{array}{l}\text { Coefficient } \\
\text { estimate }\end{array}$ \\
\hline Model & 1.44221 & 14 & 18.96 & $<0.000^{*}$ & 0.4324 \\
\hline$X_{2}$ & 0.04946 & 1 & 9.10 & $0.008^{*}$ & 0.0454 \\
\hline$X_{3}$ & 0.07833 & 1 & 14.41 & $0.002 *$ & 0.0571 \\
\hline$X_{4}$ & 0.53955 & 1 & 99.29 & $0.000^{*}$ & 0.1499 \\
\hline$X_{1} X_{4}$ & 0.00381 & 1 & 0.70 & 0.415 & 0.0154 \\
\hline$X_{2} X_{3}$ & 0.00586 & 1 & 1.08 & 0.314 & 0.0191 \\
\hline$X_{2} X_{4}$ & 0.00230 & 1 & 0.42 & 0.525 & 0.0119 \\
\hline$X_{3} X_{4}$ & 0.02874 & 1 & 5.29 & $0.035^{*}$ & 0.0423 \\
\hline$X_{1}^{2}$ & 0.20075 & 1 & 46.68 & $<0.000^{*}$ & -0.0941 \\
\hline$X_{2}{ }^{2}$ & 0.22055 & 1 & 43.45 & $<0.000^{*}$ & -0.0908 \\
\hline Pure error & 0.00001 & 6 & & & \\
\hline CorTotal & 1.52916 & 30 & & & \\
\hline \multirow[t]{4}{*}{ PRESS } & 0.500794 & & & & \\
\hline & & $R$-squared & & & \\
\hline & & Adj $R$-squared & & & \\
\hline & & Pre $R$-squared & & & \\
\hline
\end{tabular}

important in indicating the pattern of the reciprocal interactions between the variables. The linear coefficient terms $\left(X_{1}, X_{2}\right.$, $\left.X_{3}, X_{4}\right)$ and quadratic coefficient terms $\left(X_{1}{ }^{2}, X_{2}{ }^{2}, X_{3}{ }^{2}, X_{4}{ }^{2}\right)$ demonstrated significant positive responses, whereas the interaction coefficient terms between $X_{1} X_{2}, X_{1} X_{3}, X_{1} X_{4}, X_{2} X_{3}$, and $X_{2} X_{4}$ showed non-significance except for $X_{3} X_{4}$. Upon analyzing the results using multi-way ANOVA (Table 4), the $F$ value (18.96) indicated that the model was significant. The results illustrated that the most significant variables affecting the yield of O-AgNPs were initial $\mathrm{pH}$ level, $\mathrm{AgNO}_{3}$ concentration

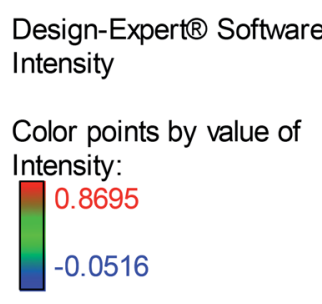

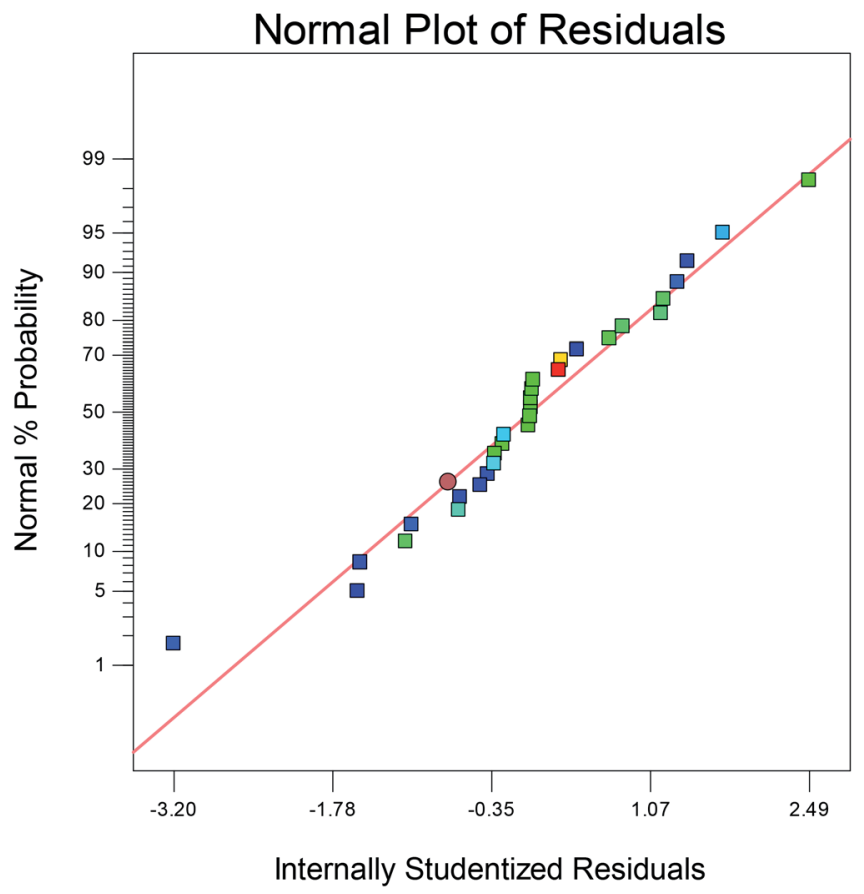

Fig. 3 Normal plot of the residuals for O-AgNP biosynthesis based on the second-order polynomial equation. 
$(\mathrm{mM})$, O. limnetica extract concentration $(\mathrm{mL})$ and incubation period (h).

The second-order regression equation represented the dependence of high AgNP yield on $X_{1}$ (initial pH level), $X_{2}$ $\left(\mathrm{AgNO}_{3}\right.$ concentration), $X_{3}$ (O. limnetica extract concentration) and $X_{4}$ (incubation period) during the reaction. The interaction between the variables was modeled using a second-order polynomial relation in terms of the coded aspects:

$$
\begin{aligned}
& Y=0.4324+0.0637 X_{1}+0.0454 X_{2}+0.0571 X_{3}+0.1499 X_{4}- \\
& 0.0941 X_{1}^{2}-0.0908 X_{2}^{2}-0.0723 X_{3}^{2}+0.0312 X_{4}^{2}+0.0190 X_{1} X_{2}+ \\
& 0.0315 X_{1} X_{3}+0.0154 X_{1} X_{4}+0.0191 X_{2} X_{3}+0.0119 X_{2} X_{4}+ \\
& 0.0423 X_{3} X_{4}
\end{aligned}
$$

where $Y$ is the predicted response (silver nanoparticle biofabrication), $X_{1}$ is the initial $\mathrm{pH}, X_{2}$ is the $\mathrm{AgNO}_{3}$ concentration, $X_{3}$ is the $O$. limnetica extract concentration and $X_{4}$ is the incubation period.

Subsequently, the coefficient of determination $R^{2}$ is used for testing the fitness of the model, in which an $R^{2}$ magnitude close to 1 exhibits a good correlation between the experimental and predicted responses. ${ }^{52}$ Our results demonstrated an $R^{2}$ value of 94.31, which is in accordance with the adjusted computed coefficient $\left(R_{\mathrm{Adj}}{ }^{2}\right)$ 89.34, thus referring to the high significance of the model. The normal plot of residuals (Fig. 3) illustrated the fitness of the model as the residuals were normally distributed on the sides of the straight line of the O-AgNPs biosynthesis, demonstrating its validation.

The contour plots (Fig. 4) illustrated the interaction between the variables studied for optimizing O-AgNP biosynthesis. Red designates the direction of the optimum condition for each of the suggested responses.

Regarding the interaction between the O. limnetica extract concentration and the incubation period (Fig. 4A), the optimum extract concentration range for the intensity of the resultant $\mathrm{O}$ AgNP preparation i.e., response value $(\lambda=430 \mathrm{~nm})$ was $3.36-6$ $\mathrm{mL}$, whereas the optimum incubation period was $43.6-48 \mathrm{~h}$. With respect to the interaction between $\mathrm{AgNO}_{3}$ concentration and incubation period (Fig. 4B), the optimum $\mathrm{AgNO}_{3}$ concentration range for the concerned response $\left(\lambda_{430 \mathrm{~nm}}\right)$ was $(0.22-0.50$ $\mathrm{mM}$ ) since the optimum incubation period was between (42.8$48 \mathrm{~h}$ ). As for the interaction between the initial $\mathrm{pH}$ level and incubation period (Fig. 4C), the optimum initial $\mathrm{pH}$ level range for the concerned response $(\lambda=430 \mathrm{~nm})$ was between 5.95 and 8.70 though the optimum incubation period lied between 41.9 and $48 \mathrm{~h}$. For the interaction between the initial $\mathrm{pH}$ level and $O$. limnetica extract concentration (Fig. 4D), the observed optimum initial $\mathrm{pH}$ level range for the calculated response $(\lambda=430 \mathrm{~nm})$ was 5.89-8.70, while the optimum O. limnetica extract concentration ranged from 2.98 to $6 \mathrm{~mL}$. In terms of the relationship between the initial $\mathrm{pH}$ level and $\mathrm{AgNO}_{3}$ concentration (Fig. 4E), it was observed that the optimum initial $\mathrm{pH}$ level range for the concerned response $\left(\lambda_{430 \mathrm{~nm}}\right)$ was $5.95-8.70$, whereas the optimum $\mathrm{AgNO}_{3}$ concentration ranged from 0.28 to $0.50 \mathrm{mM}$.

For interpreting the three-dimensional graphs, the regression model was illustrated to indicate the influences of the four investigated variables as well as the mutual possessions of each
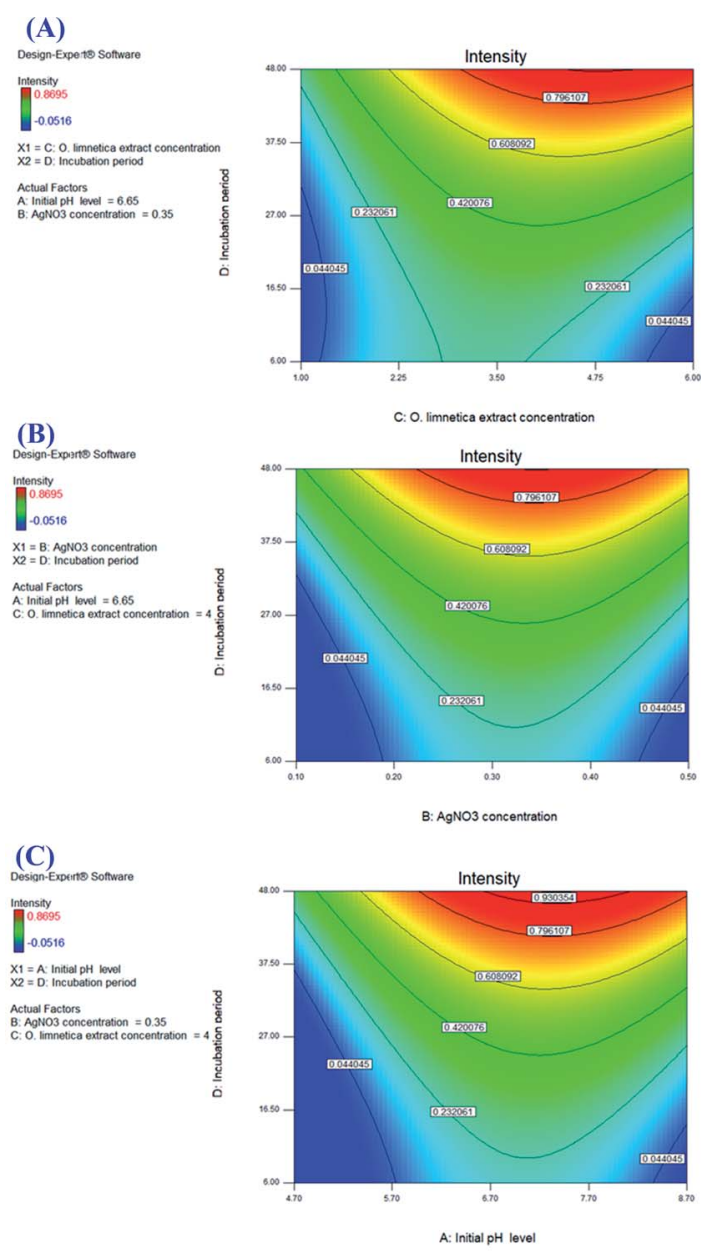

(D)

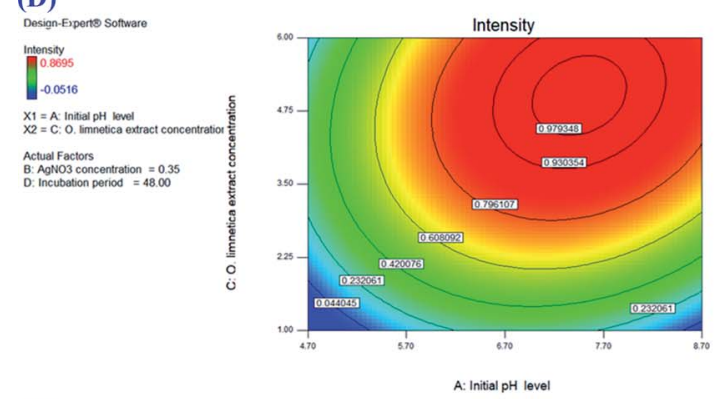

(E)

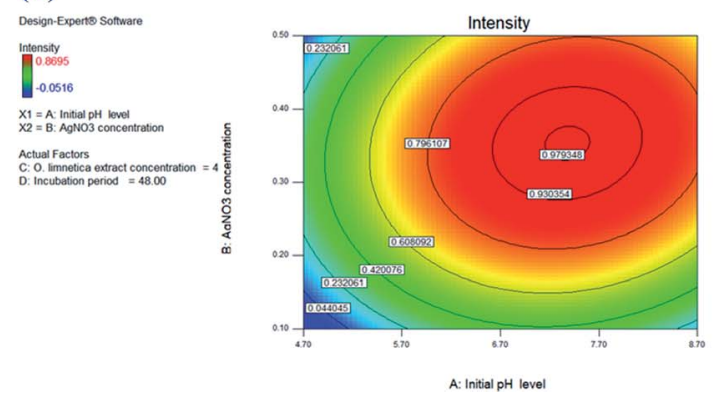

Fig. 4 Color contour plots $(A-E)$ showing the interactions between the tested variables for the maximum yield of photo-synthesized OAgNPs. 
independent unpredictable variable on O-AgNP biofabrication in terms of peak intensity at $430 \mathrm{~nm}$. The data obtained for the pair-wise interactions of the 4 variables in the silver nanoparticle biosynthesis were illustrated on the $z$-axis against the two independent variables, whereas the other two variables were at zero levels. Fig. 5A signifies the effect of $X_{1}$ (initial $\mathrm{pH}$ level) and $X_{2}\left(\mathrm{AgNO}_{3}\right.$ concentration - $\left.\mathrm{mM}\right)$, while $X_{3}$ (O. limnetica extract concentration $-4.41 \mathrm{~mL}$ ) and $X_{4}$ (incubation period -48 h) were detained at their zero points. The maximum silver nanoparticle yield was attained with the initial $\mathrm{pH}$ at 6.7, whereas the production increased rapidly with decreasing acidity accompanied by an increase in $\mathrm{AgNO}_{3}$ concentration until the middle point. Shifting the $\mathrm{pH}$ towards the alkaline side ( $\mathrm{pH} 7.7$ and $\mathrm{pH}$ 8.7) induced a gradual decrease in O-AgNP formation $(0.7 \mathrm{~nm}$ and $0.2 \mathrm{~nm})$, respectively. According to previous work, ${ }^{\mathbf{1 3}} \mathrm{pH}$ affects the electric charges of biomolecules, as well as the capping agents, inducing variations in their capability to bind and generate zero-charge metal ions. Fig. 5B illustrates the response for $X_{1}$ (initial pH level) and $X_{3}$ (O. limnetica extract concentration), while $X_{2}\left(\mathrm{AgNO}_{3}\right.$ concentration = $0.35 \mathrm{mM}$ ) and $X_{4}$ (incubation period $=48 \mathrm{~h}$ ) were set at their zero levels. The highest silver nanoparticle production was achieved at $\mathrm{pH}$ 6.7. The silver nanoparticle biosynthesis improved gradually on rising the $O$. limnetica extract concentration. ${ }^{22}$ The interaction of $X_{1}$ (initial pH level) and $X_{4}$ (incubation period) during O-AgNP biosynthesis is demonstrated in Fig. 5C, where $X_{2}\left(\mathrm{AgNO}_{3}\right.$ concentration $\left.=0.35 \mathrm{mM}\right)$ and $X_{3}(O$. limnetica extract concentration $=4.41 \mathrm{~mL}$ ) were kept at their zero levels. The maximum O-AgNPs yield was designated at $\mathrm{pH}$ 6.7. A marked increase in O-AgNP biosynthesis was noticed with an increasing incubation period. This is in agreement with the discovery of Roychoudhury et al., ${ }^{53}$ who synthesized AgNPs using Lyngbya majuscula extract after $72 \mathrm{~h}$, whereas the time required while using a cyanobacterial extract (Synechococcus sp.) ranged between $24 \mathrm{~h}$ to $72 \mathrm{~h}^{54}$ The effect of $X_{2}\left(\mathrm{AgNO}_{3}\right.$ concentration) and $X_{3}$ (O. limnetica extract concentration) on O-

\section{(A)}

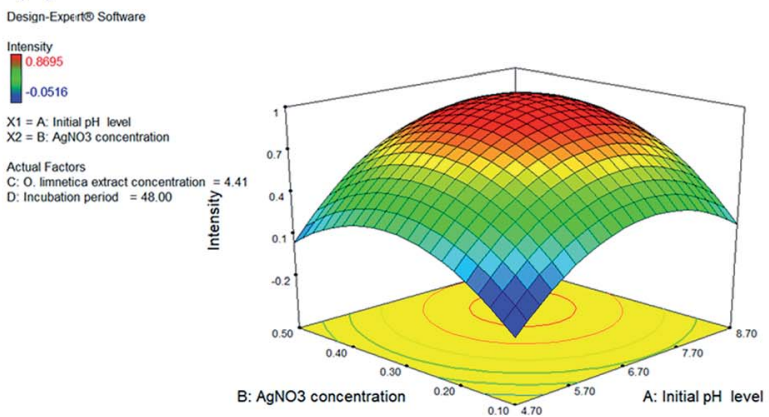

(B)

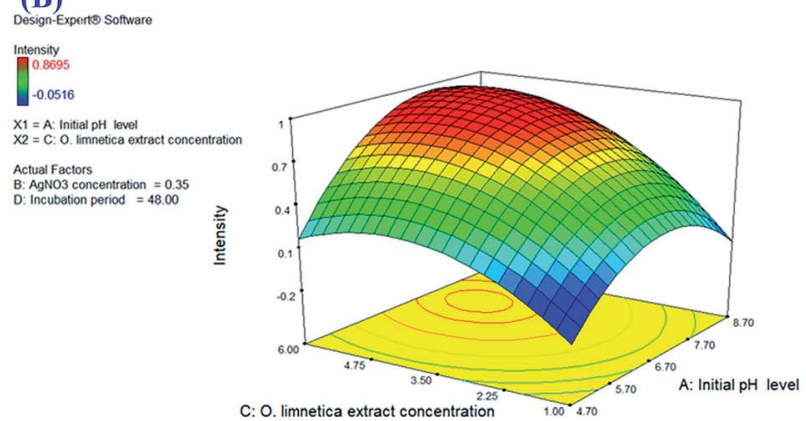

(C)

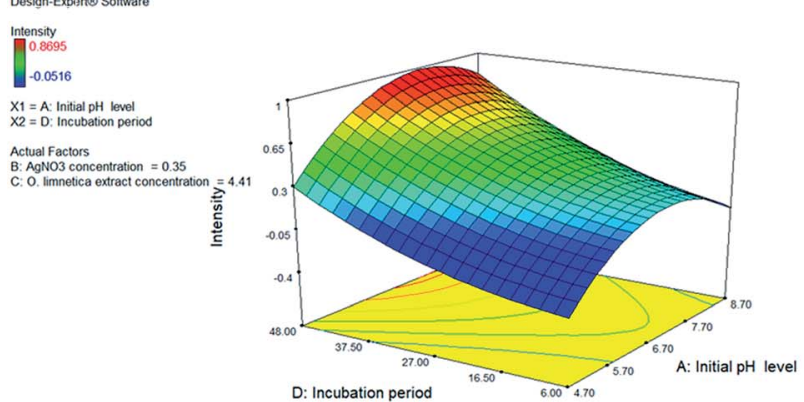

(D)

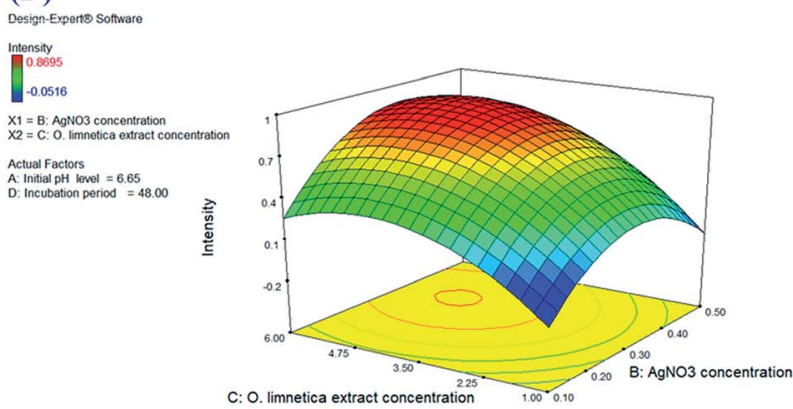

(E)

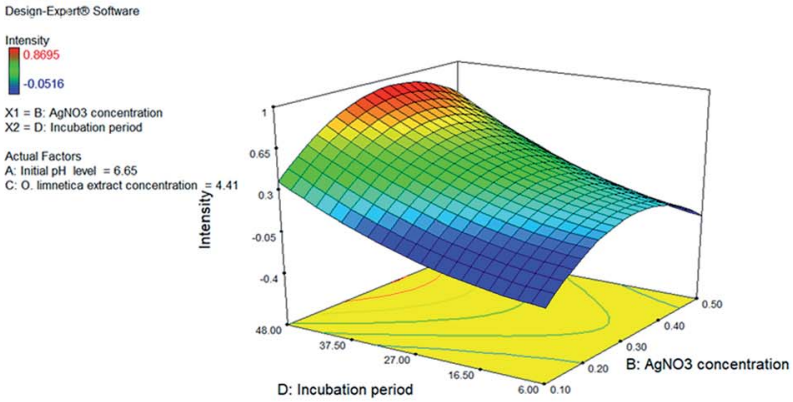

(F)

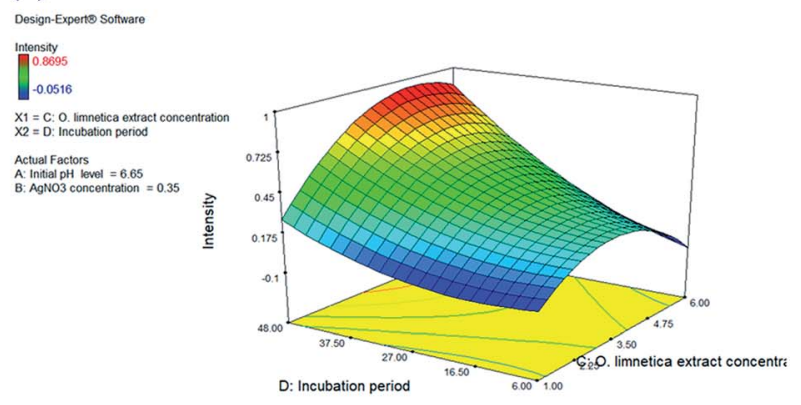

Fig. 5 Three-dimensional surface plots $(A-F)$ of the photo-synthesized O-AgNP yield showing the effect of interactions between the independent variables: initial $\mathrm{pH}$ level, $\mathrm{AgNO}_{3}$ concentration, $\mathrm{O}$. limnetica extract concentration and incubation period. 
AgNP biosynthesis is presented in Fig. 5D, whereas $X_{1}$ (initial $\mathrm{pH}$ level $=6.65$ ) and $X_{4}$ (incubation period $=48 \mathrm{~h}$ ) are set at their zero levels. Besides, there a distinct upsurge in O-AgNP biosynthesis was noticed on improving the $\mathrm{AgNO}_{3}$ concentration and $O$. limnetica extract concentration. The interaction between $X_{2}\left(\mathrm{AgNO}_{3}\right.$ concentration) and $X_{4}$ (incubation period) is illustrated in Fig. 5E, whereas $X_{1}$ (initial pH level $=6.65$ ) and $X_{3}$ (O. limnetica extract concentration $=4.41 \mathrm{~mL}$ ) were held at their zero points. The maximum O-AgNPs yield was detected near the central level of both the incubation period and $\mathrm{AgNO}_{3}$ concentration. The interaction between $X_{3}$ (O. limnetica extract concentration) and $X_{4}$ (incubation period) is demonstrated in Fig. $5 \mathrm{~F}$, whereas $X_{1}$ (initial $\mathrm{pH}$ level $\left.=6.65\right)$ and $X_{2}\left(\mathrm{AgNO}_{3}\right.$ concentration $=0.35 \mathrm{mM}$ ) were set at their zero levels. Fig. $5 \mathrm{~F}$ illustrates that the maximum O-AgNPs yield was detected on increasing the $O$. limnetica extract concentration and incubation period.

\section{Model validation}

On applying mathematical models in addition to the threedimensional interaction-surface response illustrations, the best settings for every individual response variable (i.e. singlefactor optimization) that allowed the maximum biosynthesis of O-AgNPs yielded $0.87 \mathrm{~nm}$ optical intensity against the predicated value. This illustrated a high level of model precision, which was confirmed by model validation under experimental conditions. Finally, the data revealed that the optimized values of the variables for silver nanoparticle biosynthesis were as follows: initial $\mathrm{pH}$ level (6.7), $\mathrm{AgNO}_{3}$ concentration (0.3 mM), O. limnetica extract concentration $(3.50 \mathrm{~mL})$ and incubation period $(48 \mathrm{~h})$, which were fixed for further experiments.

\section{Microstructural analysis of the O-AgNPs}

The morphological characteristics and the microstructure of OAgNPs photo-synthesized at the optimum conditions $(48 \mathrm{~h}$ at light intensity $75.90 \mu \mathrm{mol} \mathrm{m} \mathrm{m}^{-2} \mathrm{~s}^{-1}, 0.3 \mathrm{mM} \mathrm{AgNO}_{3}, 3.50 \mathrm{~mL} O$. limnetica and $\mathrm{pH}$ 6.7) and (30 min sunlight $\left(1276.51 \mu \mathrm{mol} \mathrm{m}^{-2}\right.$ $\mathrm{s}^{-1}$ ), $0.5 \mathrm{mM} \mathrm{AgNO}_{3}, 5 \mathrm{~mL}$ O. limnetica solution $\mathrm{pH}$ 6.7) were detected by SEM and TEM. First, the TEM images (Fig. 6A and B) demonstrated the shape and size of the biosynthesized $\mathrm{O}$ AgNPs. They exposed that the O-AgNPs had a quasi-spherical shape and anisotropic nanostructures, and the size range was between $6.98-23.48 \mathrm{~nm}$ in the case of light-induced synthesis $\left(75.90 \mu \mathrm{mol} \mathrm{m}^{-2} \mathrm{~s}^{-1}\right)$ and $11.58-22.31 \mathrm{~nm}$ in that using sunlight (1276.51 $\mu \mathrm{mol} \mathrm{m} \mathrm{m}^{-2} \mathrm{~s}^{-1}$ ). Moreover, the particles were welldispersed without agglomeration. ${ }^{55}$ Furthermore, Fig. 6C and D show the SEM images of O-AgNPs, which clearly elucidate the presence of smaller and monodispersed AgNPs.

\section{Particle size and zeta potential analysis of the O-AgNPs}

Zeta potential is a factor that reveals the surface charges and stability of the prepared NPs. In addition, charges have a significant influence on the nanoparticle distribution and
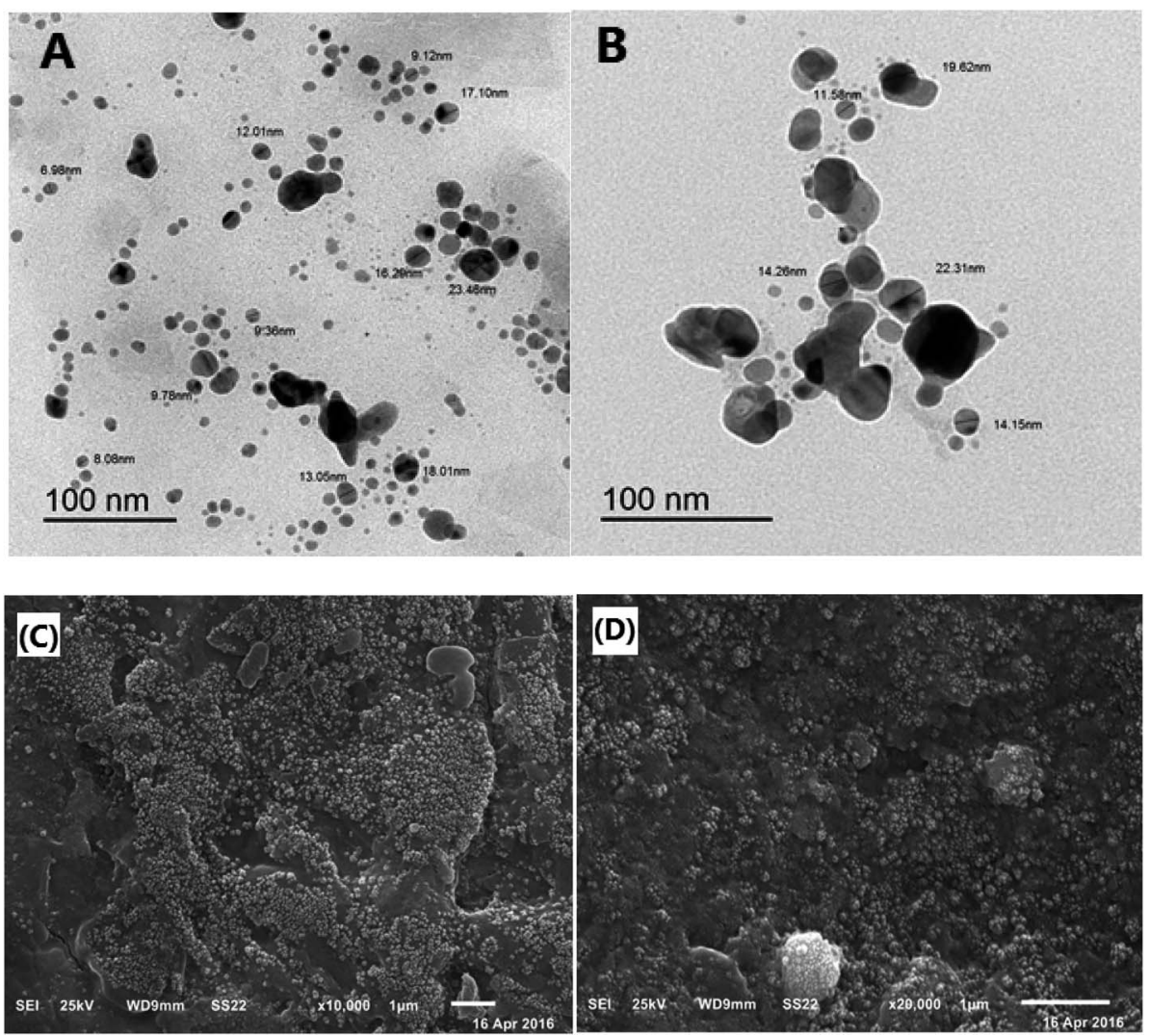

Fig. 6 Microstructural analysis of the optimized O-AgNPs: (A) \& (B) transmission electron (C) \& (D) scanning electron micrographs at the light intensities 75.90 and $1276.51 \mu \mathrm{mol} \mathrm{m} \mathrm{m}^{-2}$ (sunlight), respectively. 
cellular uptake. Charges explain the robust resistive forces amongst particles that avoid the aggregation and stabilize the NPs in the medium. The zeta potential values of O-AgNPs photosynthesized at the optimum conditions (48 h at light intensity $75.90 \mu \mathrm{mol} \mathrm{m}^{-2} \mathrm{~s}^{-1}$ ) and (30 min sunlight $1276.51 \mu \mathrm{mol} \mathrm{m}^{-2} \mathrm{~s}^{-1}$ ) were -27.4 and $-33.4 \mathrm{mV}$ with the standard deviations of 6.38 and $5.86 \mathrm{mV}$ and conductivity values of 2.24 and $2.32 \mathrm{mS} \mathrm{cm}^{-1}$, respectively (Fig. 7A and B), indicating negatively charged surfaces in the produced nanoparticles. These results are in agreement with the zeta potential of AgNPs $(-31.8 \mathrm{mV})$ biosynthesized using phycocyanin extracted from Nostoc linckia. ${ }^{\mathbf{5}}$ Moreover, El-Naggar et al. ${ }^{57}$ documented that the higher electronegativity of the phycoerythrin-mediated AgNPs, characterized by the zeta potential value equal to $-32.0 \mathrm{mV}$, may be explained by the presence of effective functional constituents that act as capping agents in the phycobiliprotein extract. The zeta potential results demonstrated that O-AgNPs were stable because of electrostatic repulsion, which can be enhanced by altering the physical or chemical capping agent. Moreover, this good stability may be due to the occurrence of bio-organic constituents that act as capping and reducing agents. Additionally, this is very vital as the nanoparticles are intended for therapeutic purposes. According to Fig. 8A and B, the DLS analysis was performed for detecting the hydrodynamic diameters of the biofabricated O-AgNPs, which were found to have average diameters of 266.2 and 272.9 at the optimum conditions $\left(48 \mathrm{~h}\right.$ at light intensity $\left.75.90 \mu \mathrm{mol} \mathrm{m} \mathrm{m}^{-2} \mathrm{~s}^{-1}\right)$ and $(30 \mathrm{~min}$ sunlight $1276.51 \mu \mathrm{mol} \mathrm{m} \mathrm{m}^{-2} \mathrm{~s}^{-1}$ ) and the polydispersity indices
(PdI) 0.451 and 0.399, respectively, which revealed that the OAgNPs were of monocular nature. ${ }^{58}$ The PdI measurement is extremely vital as it represents the nanoparticle distribution and is also used as a sign of the uniformity of size distribution. ${ }^{59}$ Salvia-Trujillo et al. ${ }^{60}$ reported that a PdI value close to 1 theoretically indicates heterogeneous size distribution of the particles, whereas a PdI of 0 denotes monocular populations. The average size value of O-AgNPs varied between TEM and DLS analysis, which might be assigned to the agglomeration of particles due to the heterogeneous aggregated dispersion behavior.

\section{Antioxidant capacity of O-AgNPs}

DPPH assay. The DPPH molecule that owns a nitrogen freeradical is susceptible to destruction by a free radical scavenger, and this is expended to study the power of oxidative compounds to function as proton radical scavengers or hydrogen donors. ${ }^{61}$ O-AgNPs are an abundant source of hydrogen as they are protected by capping agents, such as proteins, free amino acids, as well as sulfur-containing amino acid derivatives. ${ }^{22}$ The violet free-radical (DPPH) solution turned yellow after the alteration of diphenypicrylhydrazyl (free radical) to diphenylpicryhydrazine (non-free radical) due to the removal of hydrogen atoms that were bound to the O-AgNPs surface. ${ }^{62}$ Consequently, the level of color reduction was applied to evaluate the extent of the freeradical-scavenging activity of O-AgNPs. This scavenging assay revealed the effectual inhibition potentiality of O-AgNPs relative to ascorbic acid, which was used as the standard (Fig. 9). Data

(A)

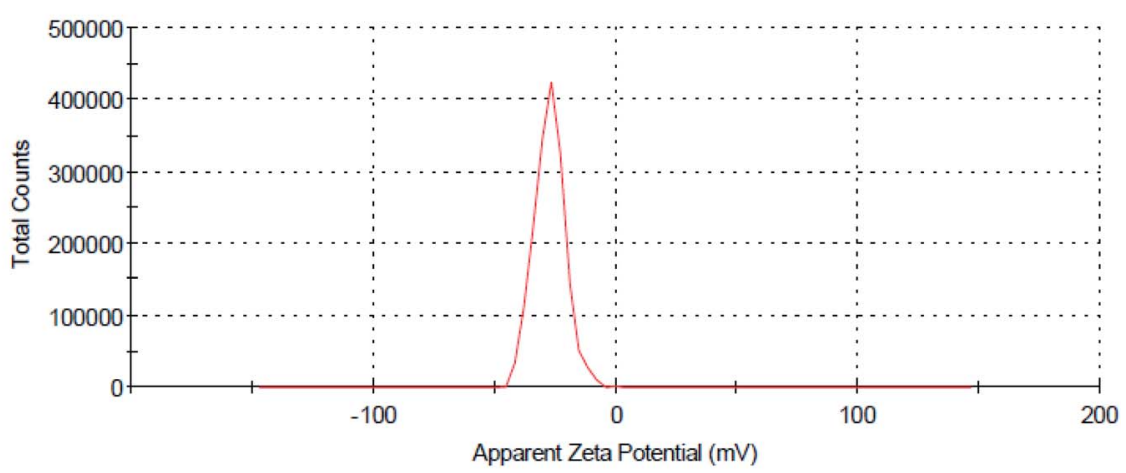

Zeta Potential Distribution

(B)

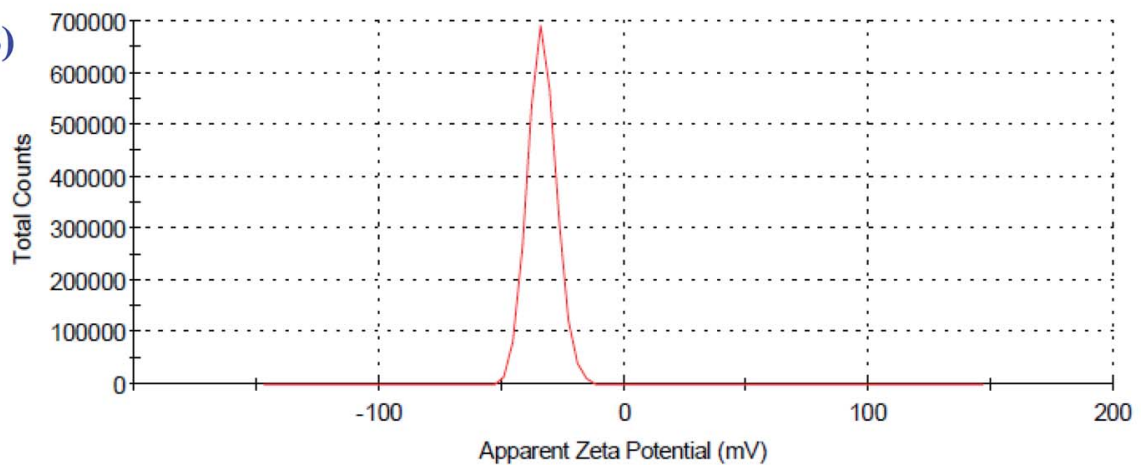

Fig. 7 Zeta potential distribution profile of the optimized photo-synthesized O-AgNPs (A) at light intensity 75.90 and (B) at $1276.51 \mu \mathrm{mol} \mathrm{m}^{-2} \mathrm{~s}^{-1}$ (sunlight). 
Size Distribution by Intensity

(A)

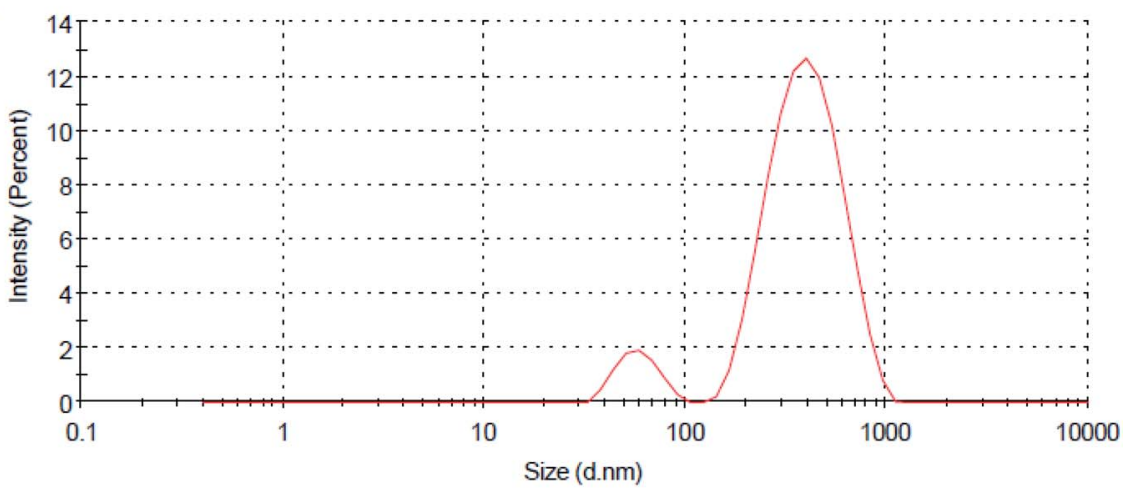

Size Distribution by Intensity

(B)

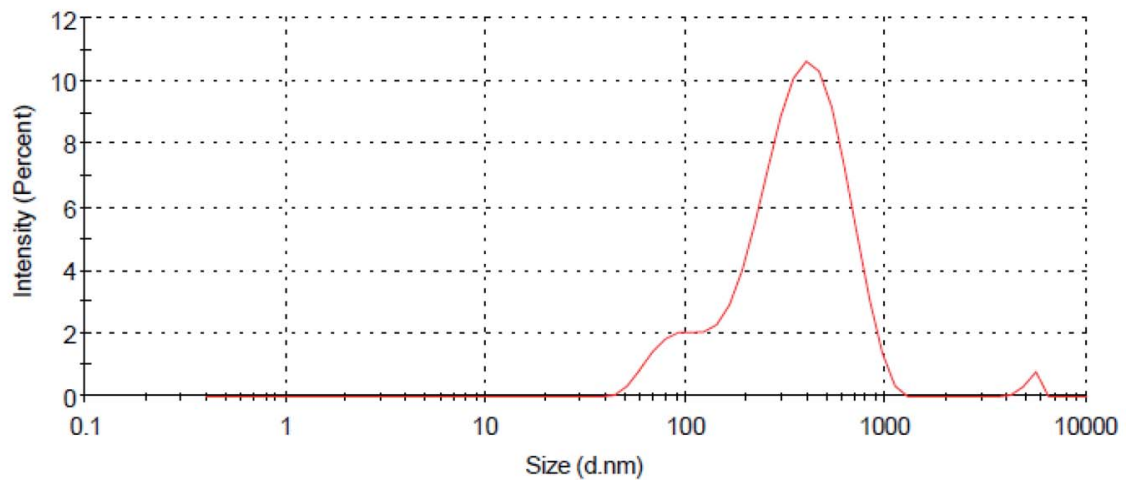

Fig. 8 Particle size distribution of the optimized photo-synthesized O-AgNPs (A) at light intensity 75.90 and (B) at $1276.51 \mu \mathrm{mol} \mathrm{m}^{-2} \mathrm{~s}^{-1}$ (sunlight).

illustrated that the DPPH-scavenging potentiality of O-AgNPs progressively increased in a dose-dependent way since the maximum inhibition action was recorded at $100 \mu \mathrm{g} \mathrm{mL}^{-1} \mathrm{O}-$ AgNPs, which provided $81.74 \%$ DPPH-scavenging activity. ${ }^{63}$ Additionally, the free-radical-scavenging activity rose, and the lesser $\mathrm{IC}_{50}$ value reflected better protective action. The $\mathrm{IC}_{50}$ value of the photo-synthesized O-AgNPs was $53.2 \mu \mathrm{g} \mathrm{mL}{ }^{-1}$. This

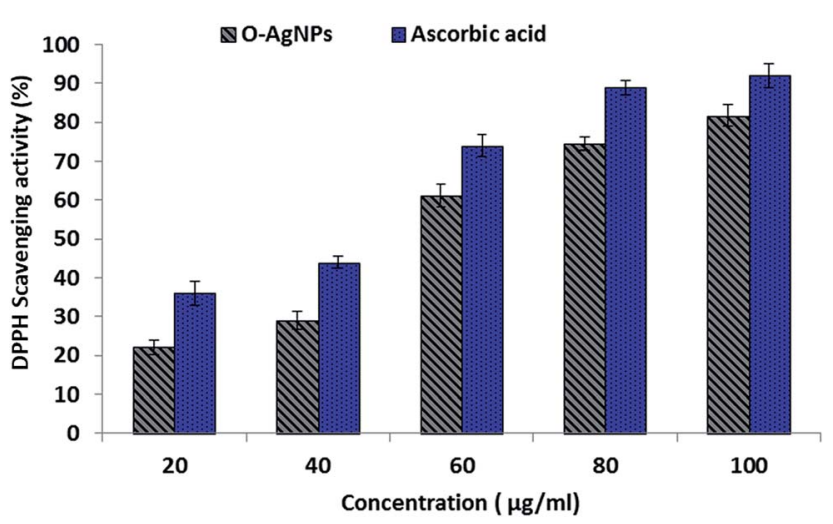

Fig. 9 DPPH free-radical-scavenging activity of the optimally photosynthesized $O$-AgNPs $\left(48 \mathrm{~h}\right.$ at light intensity $75.90 \mu \mathrm{mol} \mathrm{m} \mathrm{m}^{-2} \mathrm{~s}^{-1}$, $0.3 \mathrm{mM} \mathrm{AgNO}_{3}, 3.50 \mathrm{~mL} \mathrm{O}$. limnetica and $\mathrm{pH}$ 6.7). result indicated that the photo-synthesized O-AgNPs displayed strong antioxidant potential (DPPH-scavenging activity).

\section{$\mathrm{ABTS}^{+}$radical-scavenging (antioxidant) activity}

The ABTS assay depends on electron transfer and can detect various types of antioxidant substances. ${ }^{64} \mathrm{O}-\mathrm{AgNPs}\left(80 \mu \mathrm{g} \mathrm{mL}{ }^{-1}\right)$

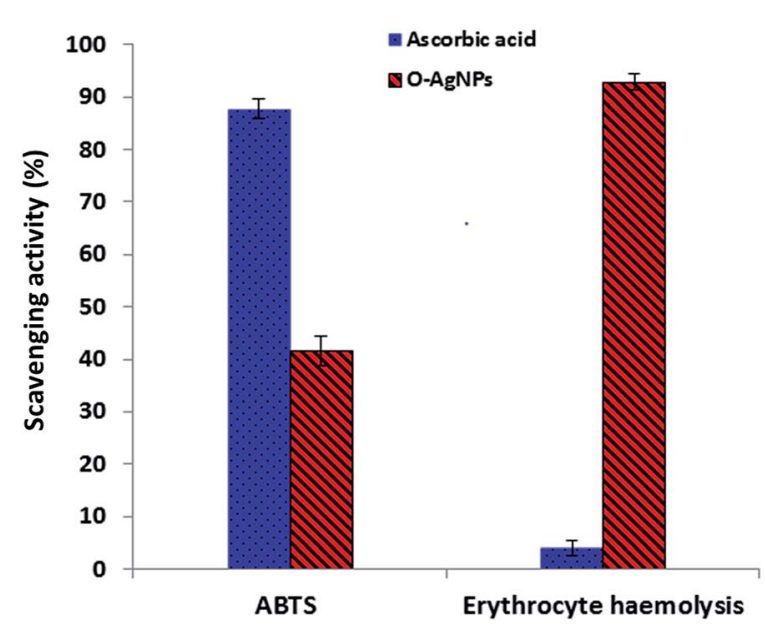

Fig. 10 Antioxidant activity screening assay of the optimally photosynthesized O-AgNPs: ABTS assay and erythrocyte haemolysis. 
demonstrated an antioxidant activity of $41.7 \%$ inhibition of the radical compared with the standard antioxidant ascorbic acid, which showed the activity of $87.8 \%$ inhibition (Fig. 10). The ABTS radical cation interacted with O-AgNPs and the hydrogen atoms were transferred to $\mathrm{ABTS}^{+}$, causing neutralization and in turn, showing its efficient scavenging activity.

\section{Anti-hemolytic assay}

Erythrocytes are oversensitive to oxidative damage due to the chemical composition of the erythrocyte membrane, which is characterized by a high content of polyunsaturated fatty acids and the presence of high oxygen concentration in addition to hemoglobin, which are effective organizers of oxidative procedures.$^{65}$ When a free radical generates lipid peroxyl radicals, the lipid membrane can be attacked and altered to lipid hydroperoxides, resulting in destructive effects on membrane biology ${ }^{65}$ The solvable hydrophilic azo-compound AAPH produces 2-amidinopropyl radicals, also-called C-radicals, via a temperature-based metabolic pathway. In the presence of oxygen, the formed C-radicals produce peroxyl radicals, resulting in increased hemolysis based on the time of erythrocyte incubation with AAPH. ${ }^{66}$ The preparation of O-AgNPs with erythrocytes, when subjected to the AAPH free radicals, demonstrated inhibition of erythrocyte hemolysis (761\%) i.e., O-AgNPs revealed anti-hemolytic potential (92.93\% inhibition) (Fig. 10). Here, hemolysis was reduced in comparison with the complete erythrocyte hemolysis attained when the erythrocytes and AAPH were incubated without O-AgNPs. Therefore, treatment with AgNPs protects erythrocytes from oxidative damage. Ascorbic acid demonstrated 4.0\% erythrocyte hemolysis. ${ }^{66}$

\section{Conclusion}

This study demonstrates a photo-induced biological method towards the green preparation of stable and quasi-spherical AgNPs using the O. limnetica aqueous extract. The central composite design (CCD) was applied to optimize the factors affecting O-AgNP biosynthesis and accomplish the maximum production of O-AgNPs (manufactured at light intensity $75.90 \mu \mathrm{mol} \mathrm{m}^{-2} \mathrm{~s}^{-1}$ ). High-productivity O-AgNP biofabrication could be attained through a facile, rapid, cost-effective, ecofriendly protocol. The optimum condition for the synthesis process under exposure to sunlight was detected through the one-factor-at-a-time approach, based on which $0.5 \mathrm{mM}$ AgNPs concentration, $5 \mathrm{~mL}$ O. limnetica solution, $\mathrm{pH} 6.7$ and $30 \mathrm{~min}$ sunlight $\left(1276.51 \mu \mathrm{mol} \mathrm{m} \mathrm{m}^{-2} \mathrm{~s}^{-1}\right)$ were determined as the optimal values. Physicochemical characterization using UV-Vis spectroscopy, FTIR, TEM, SEM and particle size and zeta potential ascertained the synthesis of O-AgNPs. The zeta potential values of the optimized photo-induced O-AgNPs were -27.4 and $-33.4 \mathrm{mV}$ with the standard deviations of 6.38 and $5.86 \mathrm{mV}$ and conductivity values of 2.24 and $2.32 \mathrm{mS} \mathrm{cm}^{-1} \mathrm{~nm}$ in the case of light-induced $\left(75.90 \mu \mathrm{mol} \mathrm{m}^{-2} \mathrm{~s}^{-1}\right)$ and sunlightinduced syntheses $\left(1276.51 \mu \mathrm{mol} \mathrm{m} \mathrm{m}^{-2} \mathrm{~s}^{-1}\right)$, respectively, indicating good stability of the produced nanoparticles. The in vitro antioxidant assays revealed that the biosynthesized O-AgNPs exhibited great radical-scavenging potential in terms of DPPH and ABTS, and erythrocyte haemolysis assays. These results indicate that O-AgNPs can be beneficial as free radical inhibitors and therapeutic agents for treating free-radical-related pathological damage.

\section{Conflicts of interest}

The authors declare no competing of interests.

\section{Acknowledgements}

AES is currently on leave from CMRDI. The authors gratefully acknowledge Faculty of science, Mansoura University, Egypt. Furthermore, AES thanks the National Research grants from MINECO “Juan de la Cierva” [FJCI-2018-037717].

\section{References}

1 A. Anwar, M. Ovais, A. Khan and A. Raza, IET Nanobiotechnol., 2017, 11, 621-629.

2 O. M. Darwesh, I. A. Matter, M. F. Eida, H. Moawad and Y.-K. Oh, Appl. Sci., 2019, 9, 1465.

3 H. J. Fallowfield, N. J. Cromar and L. M. Evison, Water Sci. Technol., 1996, 34, 141-147.

4 M. Ovais, A. T. Khalil, M. Ayaz, I. Ahmad, S. K. Nethi and S. Mukherjee, Int. J. Mol. Sci., 2018, 19, 4100.

5 J. Ai, E. Biazar, M. Jafarpour, M. Montazeri, A. Majdi, S. Aminifard, M. Zafari, H. R. Akbari and H. G. Rad, Int. J. Nanomed., 2011, 6, 1117.

6 R. Taheri-Ledari, M. S. Esmaeili, Z. Varzi, R. EivazzadehKeihan, A. Maleki and A. E. Shalan, RSC Adv., 2020, 10, 40055-40067.

7 A. Saxena, R. Tripathi, F. Zafar and P. Singh, Mater. Lett., 2012, 67, 91-94.

8 H. M. Fahmy, A. M. Ismail, A. S. El-Feky, E. S. A. Serea and W. M. Elshemey, Life Sci., 2019, 116777.

9 H. M. Fahmy, A. M. Mosleh, A. Abd Elghany, E. Shams-Eldin, E. S. Abu Serea, S. A. Ali and A. E. Shalan, $R S C A d v .$, 2019, 9, 20118-20136.

10 D. A. Selvan, D. Mahendiran, R. S. Kumar and A. K. Rahiman, J. Photochem. Photobiol., B, 2018, 180, 243252.

11 K. Govindaraju, S. K. Basha, V. G. Kumar and G. Singaravelu, J. Mater. Sci., 2008, 43, 5115-5122.

12 M. F. Lengke, M. E. Fleet and G. Southam, Langmuir, 2007, 23, 2694-2699.

13 M. F. Sanad, A. E. Shalan, S. O. Abdellatif, E. S. A. Serea, M. S. Adly and M. A. Ahsan, Top. Curr. Chem., 2020, 378, $1-43$.

14 F. K. Alsammarraie, W. Wang, P. Zhou, A. Mustapha and M. Lin, Colloids Surf., B, 2013, 103, 283-287.

15 R. Sivaraj, P. K. Rahman, P. Rajiv, S. Narendhran and R. Venckatesh, Spectrochim. Acta, Part A, 2014, 129, 255-258.

16 G. S. Murthy, Biofuels Alternative Feedstocks and Conversion Processes, 2011, vol. 12, pp. 415-437, DOI: 10.1016/B978-012-385099-7.00019-X. 
17 P. Bhunia, Reference Module in Earth Systems and Environmental Sciences Comprehensive Water Quality and Purification, 2014, vol. 3, pp. 47-73.

18 R. J. Craggs, P. J. Mcauley and V. J. Smith, Water Res., 1997, 31, 1701-1707.

19 N. González-Ballesteros, S. Prado-López, J. RodríguezGonzález, M. Lastra and M. Rodríguez-Argüelles, Colloids Surf., B, 2017, 153, 190-198.

20 R. R. R. Kannan, R. Arumugam, D. Ramya, K. Manivannan and P. Anantharaman, Appl. Nanosci., 2013, 3, 229-233.

21 R. Rippka, J. Deruelles, J. B. Waterbury, M. Herdman and R. Y. Stanier, Microbiology, 1979, 111, 1-61.

22 R. A. Hamouda, M. H. Hussein, R. A. Abo-elmagd and S. S. Bawazir, Sci. Rep., 2019, 9, 1-17.

23 H. Metzner, H. Rau and H. Senger, Planta, 1965, 65, 186-194. 24 O. H. Lowry, N. J. Rosebrough, A. L. Farr, R. J. Randall and J. Biol, Chem, 1951, 193, 265-275.

25 M. Dubois, K. A. Gilles, J. K. Hamilton, P. t. Rebers and F. Smith, Anal. Chem., 1956, 28, 350-356.

26 D. B. McDonald, W. J. Grantham, W. L. Tabor and M. J. Murphy, Appl. Math. Model., 2007, 31, 2095-2110.

27 A. Mani, S. S. Lakshmi and V. Gopal, Int. J. Biol. Pharmaceut. Res., 2012, 3, 631-633.

28 G. Minakshi, K. Vasanth, Tanupriya, K. Ilango, R. M. Kumar, A. Agrawal and G. Dubey, Int. J. Pharmacol., 2015, 11, 672680.

29 R. Re, N. Pellegrini, A. Proteggente, A. Pannala, M. Yang and C. Rice-Evans, Biol. Medd., 1999, 26, 1231-1237.

30 R. B. Walker and J. D. Everette, J. Agric. Food Chem., 2009, 57, 1156-1161.

31 Y. Morimoto, K. Tanaka, Y. Iwakiri, S. Tokuhiro, S. Fukushima and Y. Takeuchi, Pharm. Bull., 1995, 18, 1417-1422.

32 N. El-Naggar, N. A. Abdelwahed and O. M. Darwesh, J. Microbiol. Biotechnol., 2014, 24, 453-464.

33 M. Forough and K. Fahad, Turk. J. Eng. Environ. Sci., 2011, 34, 281-287.

34 A. Hamad, L. Li, Z. Liu, X. L. Zhong, H. Liu and T. Wang, RSC Adv., 2015, 5(89), 72981-72994.

35 Z. Bao and C. Q. Lan, Colloids Surf., B, 2018, 170, 251-257.

36 I. Elshahawy, H. M. Abouelnasr, S. M. Lashin and O. M. Darwesh, J. Plant Prot. Res., 2018, 58, 137-151.

37 I. Barwal, P. Ranjan, S. Kateriya and S. C. Yadav, J. Nanobiotechnol., 2011, 9, 56.

38 L. Castro, M. L. Blázquez, J. A. Muñoz, F. González and A. Ballester, IET Nanobiotechnol., 2013, 7, 109-116.

39 J. Jena, N. Pradhan, B. P. Dash, P. K. Panda and B. K. Mishra, J. Saudi Chem. Soc., 2015, 19, 661-666.

40 M. Mahdieh, A. Zolanvari and A. Azimee, Sci. Iran., 2012, 19, 926-929.

41 K. Mukherjee, R. Gupta, G. Kumar, S. Kumari, S. Biswas and P. Padmanabhan, J. Genet. Eng. Biotechnol., 2018, 16, 527536.

42 S. S. Shankar, A. Ahmad and M. Sastry, Biotechnol. Prog., 2003, 19, 1627-1631.

43 K. Zhou, Y. Hu, L. Zhang, K. Yang and D. Lin, Sci. Rep., 2016, 6, 32998.
44 F. Fassioli, R. Dinshaw, P. C. Arpin and G. D. Scholes, J. $R$. Soc., Interface, 2014, 11, 1-21.

45 V. Kumar, R. K. Gundampati, D. K. Singh, M. V. Jagannadham, S. Sundar and S. H. Hasan, J. Ind. Eng. Chem., 2016, 37, 224-236.

46 V. Ananthi, G. S. Prakash, K. M. Rasu, K. Gangadevi, T. Boobalan, R. Raja, K. Anand, M. Sudhakar, A. Chuturgoon and A. Arun, J. Photochem. Photobiol., B, 2018, 186, 232-242.

47 K.-m. Cheng, Y.-w. Hung, C.-c. Chen, C.-c. Liu and J.-j. Young, Carbohydr. Polym., 2014, 110, 195-202.

48 R. Shanmuganathan, D. MubarakAli, D. Prabakar, H. Muthukumar, N. Thajuddin, S. S. Kumar and A. Pugazhendhi, Environ. Sci. Pollut. Res., 2018, 25, 1036210370 .

49 H. M. Fahmy, R. E. S. Eldin, E. S. Abu Serea, N. M. Gomaa, G. M. AboElmagd, S. A. Salem, Z. A. Elsayed, A. Edrees, E. S. Eldin and A. E. Shalan, RSC Adv., 2020, 10, 20467-20484.

50 K. Venugopal, H. Rather, K. Rajagopal, M. Shanthi, K. Sheriff, M. Illiyas, R. Rather, E. Manikandan, S. Uvarajan and M. Bhaskar, J. Photochem. Photobiol., B, 2017, 167, 282-289.

51 I. Šeděnková, M. Trchová, J. Stejskal and J. Prokeš, ACS Appl. Mater. Interfaces, 2009, 1, 1906-1912.

52 L. Reddy, Y.-J. Wee, J.-S. Yun and H.-W. Ryu, Bioresour. Technol., 2008, 99, 2242-2249.

53 P. Roychoudhury, P. K. Gopal, S. Paul and R. Pal, J. Appl. Phycol., 2016, 28, 3387-3394.

54 S. Keskin, N. Oya, N. Koçberber Kılıç, G. Dönmez and T. Tekinay, J. Nano Res., 2016, 40, 120-127.

55 A. K. Singh, R. Tiwari, V. Kumar, P. Singh, S. R. Khadim, A. Tiwari, V. Srivastava, S. Hasan and R. Asthana, J. Photochem. Photobiol., B, 2017, 166, 202-211.

56 N. E.-A. El-Naggar, M. H. Hussein and A. A. El-Sawah, Sci. Rep., 2017, 7, 10844.

57 N. E.-A. El-Naggar, M. H. Hussein and A. A. El-Sawah, Sci. Rep., 2018, 8, 8925.

58 A. Banerjee, D. Das, S. G. Rudra, K. Mazumder, R. Andler and R. Bandopadhyay, J. Polym. Environ., 2020, 28, 242-256.

59 A. P. Nayak, W. Tiyaboonchai, S. Patankar, B. Madhusudhan and E. B. Souto, Colloids Surf., B, 2010, 81, 263-273.

60 L. Salvia-Trujillo, M. A. Rojas-Graü, R. Soliva-Fortuny and O. Martín-Belloso, Food Hydrocolloids, 2013, 30, 401-407.

61 M. H. Hussein, G. S. Abou-ElWafa, S. A. Shaaban-Dessuuki and N. I. Hassan, Int. J. Pharm., 2015, 11, 432-439.

62 P. Molyneux and Songklanakarin, J. Sci. Technol, 2004, 26, 211-219.

63 T. Rajkumar, A. Sapi, G. Das, T. Debnath, A. Ansari and J. K. Patra, J. Photochem. Photobiol., B, 2019, 193, 1-7.

64 M. H. Hussein, R. A. Hamouda, A. M. A. Elhadary, M. A. Abuelmagd, S. Ali and M. Rizwan, Environ. Sci. Pollut. Res., 2019, 26, 31998-32012.

65 M. R. Clemens and H. D. Waller, Chem. Phys. Lipids, 1987, 45, 251-268.

66 E. Niki, Meth. Enzymo., Elsevier, 1990, pp. 100-108. 